\title{
A Review of Active Hand Exoskeletons for Rehabilitation and Assistance
}

\author{
Tiaan du Plessis ${ }^{1, *(\mathbb{D})}$, Karim Djouani ${ }^{2,3}$ and Christiaan Oosthuizen ${ }^{1}$ (D) \\ 1 Department of Mechanical and Mechatronics Engineering, Tshwane University of Technology, \\ Pretoria 0001, South Africa; oosthuizencc@tut.ac.za \\ 2 F'SATI, Department of Electrical Engineering, Tshwane University of Technology, Staatsartillerie Rd., \\ Pretoria 0183, South Africa; djouanik@tut.ac.za \\ 3 LISSI LAB, University Paris Est-Creteil, Avenue du General de Gaulle, 9400 Creteil, France \\ * Correspondence: 215661695@tut4life.ac.za
}

\section{check for} updates

Citation: du Plessis, T.; Djouani, K.; Oosthuizen, C. A Review of Active Hand Exoskeletons for Rehabilitation and Assistance. Robotics 2021, 10, 40. https://doi.org/10.3390/robotics10 010040

Received: 14 January 2021

Accepted: 10 February 2021

Published: 3 March 2021

Publisher's Note: MDPI stays neutral with regard to jurisdictional claims in published maps and institutional affiliations.

Copyright: (c) 2021 by the authors. Licensee MDPI, Basel, Switzerland. This article is an open access article distributed under the terms and conditions of the Creative Commons Attribution (CC BY) license (https:// creativecommons.org/licenses/by/ $4.0 /)$.

\begin{abstract}
Disabilities are a global issue due to the decrease in life quality and mobility of patients, especially people suffering from hand disabilities. This paper presents a review of active hand exoskeleton technologies, over the past decade, for rehabilitation, assistance, augmentation, and haptic devices. Hand exoskeletons are still an active research field due to challenges that engineers face and are trying to solve. Each hand exoskeleton has certain requirements to fulfil to achieve their aims. These requirements have been extracted and categorized into two sections: general and specific, to give a common platform for developing future devices. Since this is still a developing area, the requirements are also shaped according to the advances in the field. Technical challenges, such as size requirements, weight, ergonomics, rehabilitation, actuators, and sensors are all due to the complex anatomy and biomechanics of the hand. The hand is one of the most complex structures in the human body; therefore, to understand certain design approaches, the anatomy and biomechanics of the hand are addressed in this paper. The control of these devices is also an arising challenge due to the implementation of intelligent systems and new rehabilitation techniques. This includes intention detection techniques (electroencephalography (EEG), electromyography (EMG), admittance) and estimating applied assistance. Therefore, this paper summarizes the technology in a systematic approach and reviews the state of the art of active hand exoskeletons with a focus on rehabilitation and assistive devices.
\end{abstract}

Keywords: hand exoskeletons; rehabilitation; active assistive devices; robotic orthosis; hand exoskeleton requirements

\section{Introduction}

The idea of developing robots that can be attached to humans to assist in certain tasks is not new. This idea was first realized in the 1960s when the first full-body exoskeleton was developed to amplify human power [1]. Various research was done over the years, and in the late 1980s, one of the first hand exoskeletons was developed, which mostly consisted of sensors contained in a glove. This device was mainly developed for haptic feedback in teleoperation projects [2]. Various other attempts and patents were created that led to the technology of today [3]. The technology of exoskeletons was first developed for military purposes, but the interest in the medical and rehabilitation areas soon sparked, which led to numerous attempts to solve one problem: the problem of rehabilitating and assisting individuals with disabilities to improve their quality of life, especially hand impairments.

Today, hand exoskeletons and exoskeletons in general can be found in various areas, such as in the medical field for rehabilitation and assistance, in the military and industrial field for power amplification, and in the consumer field for haptic feedback purposes. Although in some areas, the technology of exoskeletons is still actively being researched, it is clear that these devices will become part of our everyday accessories in the future [4]. 
One of the main research focuses is in the medical field due to an increase in disabilities caused by various factors such as accidents, diseases, or general aging of the population. According to the World Health Organization, more than a billion people live with some sort of disability, and the number will keep on increasing as the population ages [5]. Older people have a higher risk of obtaining disability due to chronic health conditions such as diabetes, cardiovascular disease, and/or mental illness. Any disability especially those that affect the motor skills of the individual can experience a drastic decrease in the quality of life. It has been identified that people with disabilities are more likely to be unemployed and generally earn less when employed, have higher poverty rates than those who are not disabled, and usually depend more on others for activities of daily life (ADL) [5].

Most upper limb disabilities are located at the hand or forearm, which usually occurs due to injuries [6]. Cervical or neck injuries are one of the main causes of quadriplegia or the loss of hand functions. Injuries sustained at the C-5 vertebra of the spinal cord usually affect the functions of the wrist and hand but do not affect the shoulder or bicep of the arm. These spinal cord injuries can occur from trauma (car accident, gunshot, etc.) or a disease such as polio, spina bifida, amyotrophic lateral sclerosis (ALS), or cerebral vascular diseases (stroke) [7]. Strokes and spinal cord injuries (SCI), as mentioned above, are some of the main causes of hand disabilities due to hemiplegia [8]. These injuries and diseases can affect one's life greatly; therefore, engineers have been designing robotics to work in tandem with humans to assist with these issues and improve their quality of life.

The traditional way of rehabilitating a human limb or body part has generally been through a physical therapist. These treatments involve the patient being passive while the therapist does the active movements. Studies have shown that the active involvement of the patient can strengthen and improve their motor learning as well as their cognitive-motor skills, which can lead to a more rapid recovery [9]. The cost of therapy over a prolonged time can get expensive, and the need for the patient to go to the therapist can lead to a loss of interest. This can cause the patient to struggle and have a decrease in their quality of life. This issue gave birth to a need for active systems that can assist both therapists and patients. These robotic systems can assist the therapy process by taking over the physical load of therapists, and, longer and more intense training periods can be executed for a more rapid recovery while better repetitive action exercises are accomplished [3]. It has also been shown by Lum et al. and Staubli et al. that highly repetitive task training can help the recovery of motor functions $[10,11]$. Therapists can also track the progress of the patients by analyzing the sensory data obtained from the exoskeletons. It has been shown that robotic systems assisting therapists can improve the recovery of patients; this can be seen through the hand exoskeleton "HEXORR" and the clinical experiments that they have conducted [12]. With the rise of active hand exoskeleton systems, one major goal is also to allow the patient to train in the comfort of their own home, be more mobile, and have more independence thanks to the development of portable devices.

The main function of a hand exoskeleton is to recover or restore the motor capabilities of a patient with impaired hands. Hands are the most important part of the body, besides the brain, because hands are the main part for exploring your curiosity and interaction between objects by grasping and manipulating them. Just imagine yourself doing a mindless task with your hands, such as making coffee. You use your hands to open the coffee lid, use a spoon, pour water, etc., and this is just an example of a simple everyday task. Imagine these actions if your hands are unavailable? This can severely affect your quality of life and your ability to accomplish activities required for daily living (ADL).

Exoskeletons have been proven, through studies such as [10,11], to benefit the rehabilitation process as well as minimize the strain on the muscle and reduce localized muscle activity. A study was done by $[13,14]$, assessing the effects of upper limb exoskeleton vests on shoulder motion, balance, and spinal loading. A reduction in shoulder muscle activity was found to be up to $45 \%$, depending on the workload. To reduce muscle activity in one area, wearable devices increases the load on other parts of the musculoskeletal system by transferring the load. This can happen in wearable devices, but rehabilitation stationary 
devices transfer the load away from the body, minimizing load transfer. This is an area that needs to be explored more in depth as the technology advances.

The focus of this paper will mainly be placed on medical hand exoskeletons and the technology surrounding them (Figure 1). This will include rehabilitation and assistive active hand exoskeletons, but some examples are given for haptic and augmentation devices as additional information. Most of the current hand exoskeletons were reviewed and analyzed with the main purpose of evaluating the technology and compiling these devices together for future designers to improve the technology. The author recommends reading $[3,15-21]$ articles that capture other information regarding the technology surrounding hand exoskeletons especially $[3,20,21]$; these papers focus on soft robotic technologies including artificial muscles and tendon driven mechanisms. Article [19] is a good reference to determine the future trend of robotic systems for human benefit as well as the naming convention of these technologies. The knowledge of hand anatomy and biomechanics is important for background information to interpret the designs of the exoskeletons; therefore, Section 3 is devoted to this knowledge.

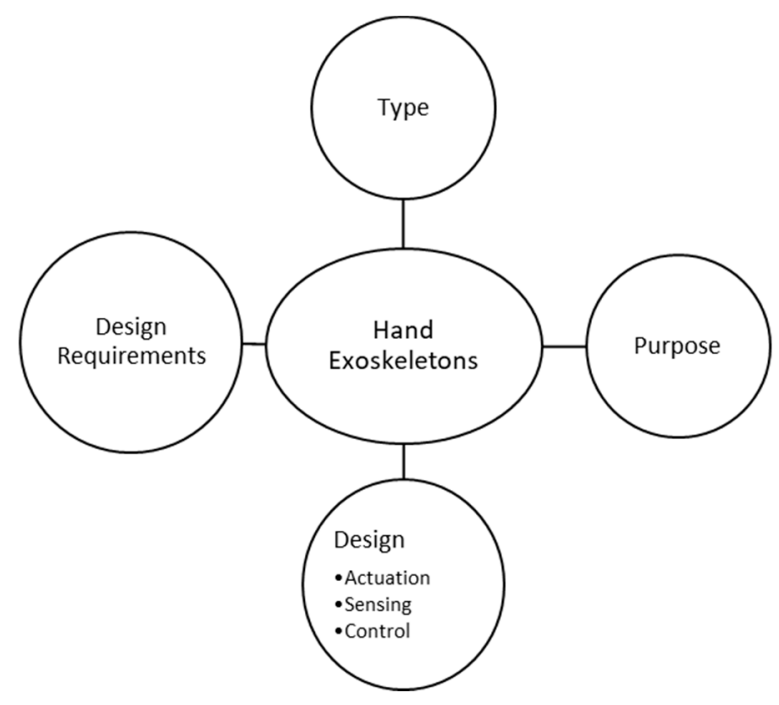

Figure 1. The basic outline of the contents covered in this paper.

\section{Method}

A narrative review method approach was taken in a chronological order using several online databases, i.e., ResearchGate, IEEE/ASME, ScienceDirect, Google Scholar, Frontiers, and MDPI, to capture the various technologies explored and implemented from the year 2010 onward. Keywords entries such as "Hand exoskeletons" and "Active hand rehabilitation" were used to search the databases. The results were further filtered by using keywords such as "Rehabilitation", "Assistive", "Wearable", "Portable", and "compliant mechanisms". After obtaining the search results, a set of inclusion and exclusion criteria were implemented to further narrow down the literature search.

\subsection{Inclusion and Exclusion Criteria}

\subsubsection{Inclusion Criteria}

- The device described was a wearable active device that had some sort of actuating unit for delivering the appropriate range of motion (ROM) for the hand.

- The paper is accessible to the authors and is a scientific article written in the English language.

- The study presented the mechanical and electrical aspects of the designed hand exoskeleton in four of the following attributes: active degree of freedom (DOF), output force, intended action, ROM, weight, or control methods.

- The device actuates at least one finger actively. 
- The device is intended for rehabilitation or assistive purposes.

\subsubsection{Exclusion Criteria}

- The device was intended for other body parts or limbs other than the hands.

- The device was a prosthetic or anthropomorphic hand for lost limbs.

- The paper or article was published in any language other than English.

- The study had insufficient information on the design, which made the analysis unclear.

There are numerous studies and devices aimed at rehabilitating or assisting other major joints or limbs of the body for activities of daily living and improving the life quality of those who need it most, which are not included in this review due to the focus being placed on the hand. Exoskeletons also exist for other purposes such as augmenting human power to minimize the body strain on healthy individuals as well as devices for haptic and teleoperation applications. Only a few devices were considered to obtain additional information, but other than that, the majority were excluded. Prosthetics were also excluded due to other design requirements and it being the anatomical replacement for a body part, whereas the focus for rehabilitation or assistance is to regain the function of an impaired body part. Last but not least, passive devices were also handled the same way as augmentation and haptic devices, where only some were considered for additional information and the majority were excluded because this study focused on the technology of active rehabilitation and assistive devices.

\subsection{Framework}

A framework was developed to analyze the relatively large number of studies found in the literature search. The purpose was to extract the various technologies used in developed devices and present them in a logical and systematic order for future designers to gain knowledge of existing methods. The devices were categorized according to their design type (rigid or soft) followed by their purpose (rehabilitation, assistance, augmentation, or haptic). Then, design requirements were extracted followed by an extensive breakdown of the actuation, power transmission, and sensing as well as the control methods used by each device. Although this framework does not address the exact building process of the devices, its potential lies in the various building blocks that are required to design a device and the methods already explored.

\section{Hand Anatomy and Biomechanics}

The hand is the most distal part of the upper limbs and is an engineering marvel on its own. It plays a crucial role in the development of the brain's motor functions and skills; furthermore, it is also the organ that interacts with human curiosity, each other, and the surroundings. The hand is used to communicate, express emotion, and manipulate the environment. The hand executes the commands given from the brain through neurons that travel through the nervous system to the respective areas such as muscles to articulate certain body parts [22]. Learning to use your hands from a young age strengthens your cognitive skills and simultaneously develops many other areas in our brain. By exploring the world with your hands, you develop hand-eye coordination, strengthen your proprioception, improve gross motor and fine motor skills, and improve the visual tracking and discrimination of objects [23]. This is an indication of the import role the hands have in your development.

The hand is one of the most complex structures in the human body due to its compact size (consisting of bones, joints, muscles, tendons, nerves, and blood vessels), large executable degree of freedom (DOF), and range of motion (ROM). In total, there are 27 bones [24], 36 articulations [25], and 39 active muscles [25], which are all designed to make the hand the most versatile tool of the human body. The hand has four fingers and an opposing thumb and offers 21 DOF [25]. 


\subsection{Bones and Joints}

The hand can be divided into three sections: the wrist (Carpus), palm (Metacarpus), and fingers (Phalanges) [25].

\subsubsection{The Wrist (Carpus)}

The wrist connects the palm and fingers to the bones of the forearm (Radius and Ulna) and is a gateway for the blood vessels, tendons, and nerves. The wrist is also known as the carpus, which consists of individual bones known as the carpal bones. The carpus can be considered as a functional or morphological joint. A functional joint in the sense of a single joint with two DOF (Flexion/Extension and Radial deviation/Ulnar deviation). A morphological joint is concerned about all the bones and articulations in the wrist. It consists of two separate joints, proximal and distal joints, with two DOF for each joint. The wrist consists essentially eight small bones (carpal bones) (Figure 2a) (seven regular bones and one sesamoid bone), which can be divided into a proximal and distal row. The proximal row consists of the Scaphoid, Lunate, Triquetrum, and Pisiform (sesamoid bone). The distal row consists of the Trapezium, Trapezoid, Capitate, and Hamate. All these bones are connected via ligaments and have a gliding motion between each other. For the exploration of hand exoskeletons, the wrist will be taken as a functional joint.

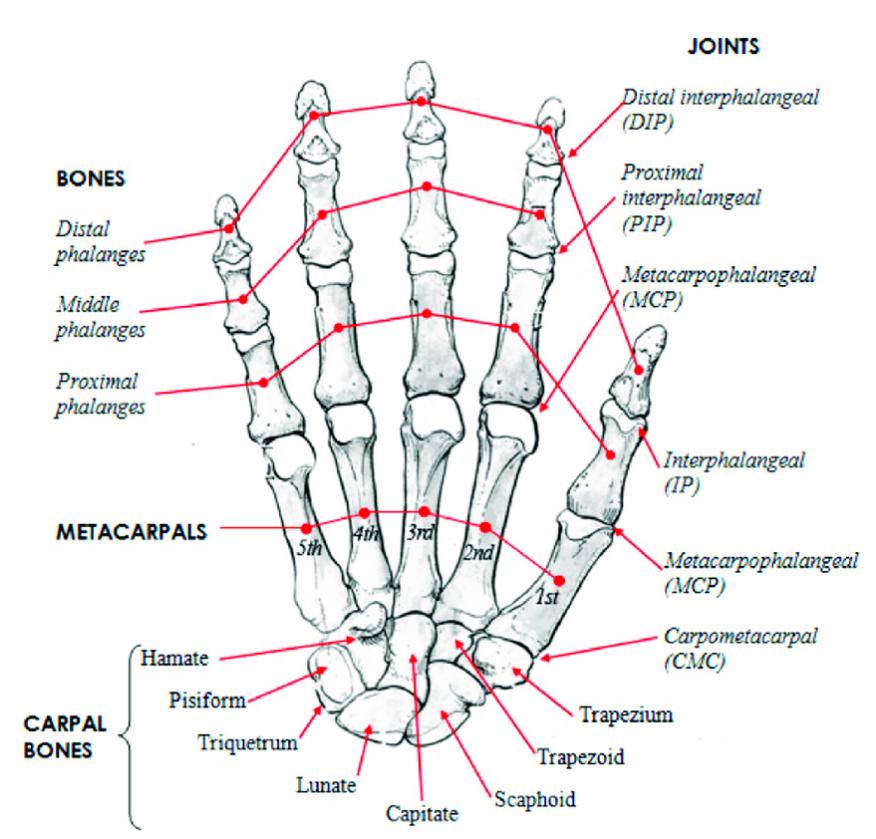

(a)

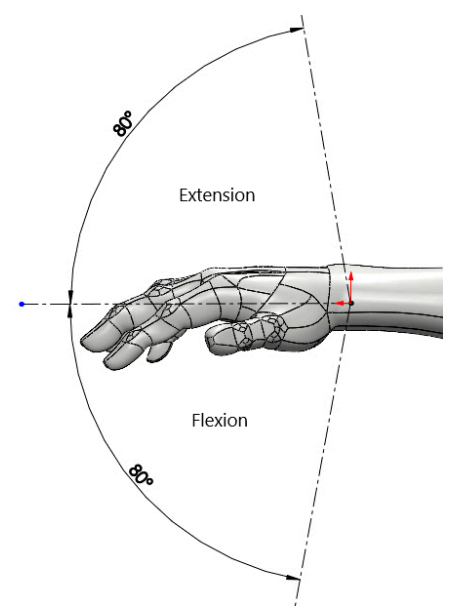

(b)

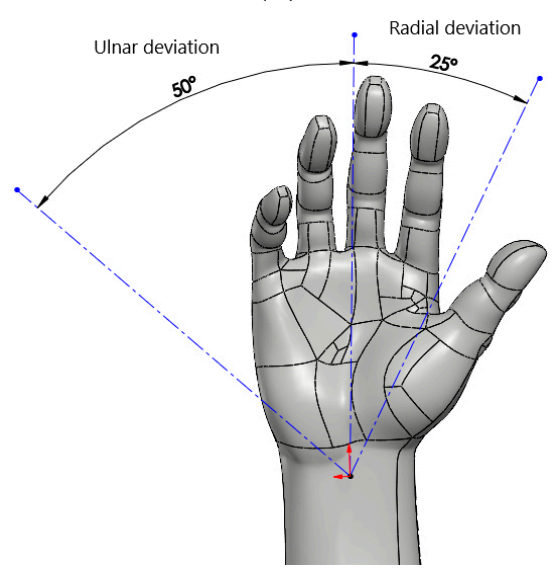

(c)

Figure 2. The internal bone structure of the hand as well as the wrist movements. (a) The skeletal structure of the hand, indicating the various bones and joints. The figure is taken from [26], which is an open-access article. (b) Indicates the flexion and extension motion of the wrist with its maximum range of motion (ROM). (c) Indicates the radial and ulnar deviation of the wrist with its maximum ROM of the right hand. 
The range of motion is always measured from the mid-carpal joint at a neutral position. Flexion can be around $80^{\circ}$ and extension also around $80^{\circ}$ (Figure 2b). Radial deviation is around $15^{\circ}-25^{\circ}$, and Ulnar deviation is around $40^{\circ}-50^{\circ}$ (Figure $2 \mathrm{c}$ ). Most hand exoskeletons do not consider the motion of the wrist; therefore, device designs either hold the wrist stationary or allow the wrist only to flex or extend.

The joint that connects the distal carpal bones to the base of the metacarpal bones is known as the carpometacarpal joints (CMC joints).

\subsubsection{The Palm (Metacarpus)}

The palm consists of five bones known as the Metacarpals including the thumb (Figure 2a). These bones have a concave curve palmar ward to them and connect the finger phalanges to the carpus (wrist). The most important task of the metacarpal bones is to support the grasping function, and it serves as a bridge for the nerves of the fingers.

The heads of the 2 nd and 3rd metacarpal bones are pronated concerning the base and the heads of the 4 th and 5 th metacarpals are supinated toward the base. The longitudinal axis of the 3rd metacarpal is directed toward the scaphoid, and that of the 4th and 5th metacarpal is toward the lunate (Figure 2a). The most limited ROM is in the 2nd and 3rd metacarpal. They are the stable columns of the palm, and the 4 th and 5 th are somewhat more flexible.

\subsubsection{The Fingers (Phalanges)}

The fingers are named the Thumb, Index, Middle, Ring, and Little, which comprises of bones called the phalanges. The thumb has two phalanges (proximal and distal), while the rest have three phalanges (proximal, middle, and distal) (Figure 2a). The fingers are also numbered from 1 to 5 starting at the thumb. The fingers alone are also commonly referred to as "digits".

\subsubsection{Joints (Articulations)}

The metacarpophalangeal (MCP) joint (commonly known as the knuckles) has two DOF, which involves abduction/adduction and flexion/extension (Figure 3), which is also commonly referred to as a condylar joint. The proximal interphalangeal joint (PIP) together with the MCP joint is the most important functional unit for grasping, gripping, and making a fist. The PIP joint is a hinge joint, which only consists of flexion and extension i.e., 1 DOF. The PIP joints of the index and middle fingers exhibit ulnar deviation, and those of the ring and little finger exhibit radial deviation. The distal interphalangeal joints (DIP) of the digits are similar to the PIP joints with 1 DOF.
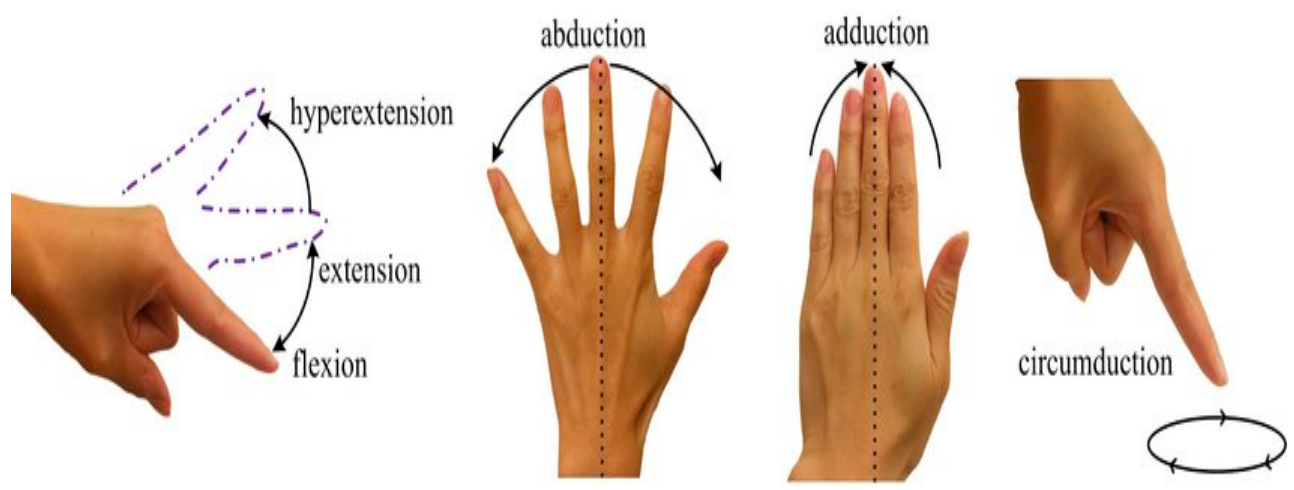

Figure 3. Indicates the flexion, extension, abduction, and adduction of the 2 nd to 5 th digits of the hand. This diagram was taken from [27], which is an open-source article.

ROM for the 2nd-5th digits [25]:

- MCP joints: Flexion approximately $90^{\circ}$, extension approximately $40^{\circ}$, abduction approximately $15^{\circ}$ and adduction approximately $15^{\circ}$ 
- PIP joints: Flexion approximately $130^{\circ}$, extension approximately $0^{\circ}$

- DIP joints: Flexion approximately $90^{\circ}$, extension approximately $30^{\circ}$

\subsubsection{The Thumb}

The thumb is the first, strongest, and most mobile digit of the hand due to its range of motion (ROM). The thumb is a special digit since it can oppose the other fingers and contribute significantly to the gross motor and fine motor grasping functions of the hand. The complex CMC joint of the thumb, along with its nine muscles, is what gives it a great advantage over the other digits. The CMC joint is essentially a saddle joint, and at a neutral position, the axis of the metacarpal forms a $30^{\circ}$ angle with the 2nd metacarpal.

The functional joints of the thumb are the CMC joint, the metacarpophalangeal joint (MCP), and the interphalangeal joints of the digit itself (Figure 2a).

The functional unit of the thumb is:

- The opposition.

- The coordinated movement between the thumb, index, and middle finger.

- The little and ring finger as a strengthening unit of the fist.

\subsubsection{Movement of the Thumb}

The CMC joint gives the thumb two DOF. The 1st DOF is abduction and adduction around the axis through the base of the $1 \mathrm{st} \mathrm{MCP}$ and makes a $45^{\circ}$ angle to the plane of the extended hand. The 2nd DOF is flexion and extension [25]. There is circumduction to some extent in the CMC joint.

The ROM [25]:

- Approximately $35^{\circ}$ abduction and $25^{\circ}$ adduction

- Approximately $25^{\circ}$ flexion and $45^{\circ}$ extension

- Approximately $10^{\circ}$ rotation in $\mathrm{CMC}$ joint

The thumb MCP and IP joints are involved in all movements of the thumb.

\subsection{Muscles}

The movements and articulation of the hand are coordinated and executed by muscles. These muscles are located in the forearm (known as extrinsic muscles) and between the fingers and metacarpals (known as intrinsic muscles). Essentially, the digit's flexion and extension muscles are located in the forearm and are connected through tendons to the respective phalanges. The thumb alone has nine muscles (as mentioned before) to execute the various grip types and opposition. Abduction and adduction of the digits are mainly produced by the intrinsic muscles, but most of the muscles have multifunction capabilities. For a more detailed explanation, it is recommended to read [25].

\subsection{Overall Types of Hand Grips}

Many hand grips are possible and used every day, depending on the task required and the type of objects manipulated. Therefore, the main and most used grips can be classified into three main categories namely Power, Precision, and Hook grips [28,29].

- Power grip indicates that the object is clamped between the partly flexed fingers and the palm. The thumb applies counter pressure, which lies in the plane of the palm. Different forms of a power grip exist such as where the thumb is opposed rather than adducted to grasp an object such as a class or bottle (cylindrical grasp) (Figure 4a,b). 


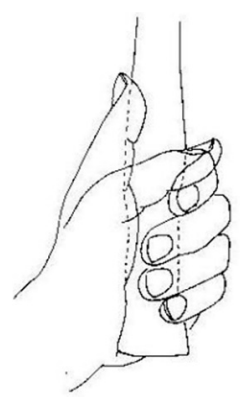

(a)

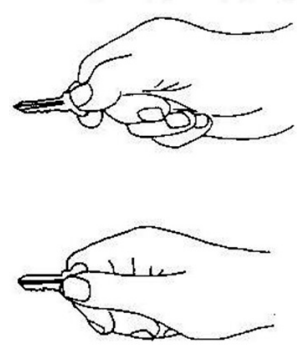

(c)

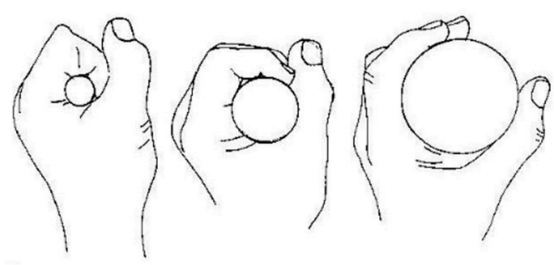

(b)

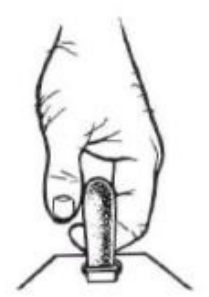

(d)

Figure 4. Common types of hand grips that are used every day. (a) Indicates the power grip with the thumb in-plane with the palm. The illustration is taken from [30]. (b) Illustrates another type of power grip called the cylindrical grip. The diagram is also from [30]. (c) Represents a precision grip, more specifically a key grip [30]. (d) Illustrates a hook grip where the thumb is not involved. The illustration is from the free access paper [24].

- Precision grip is when the object may be pinched between the fingertips and opposed thumb. Many grips have also been identified such as the tip-to-tip, tip-to-pad, key grip, tripod grip (for holding a pen), etc. (Figure 4c).

- Hook grip forms part of the power grip family but is different in the sense that the thumb is rarely used. This grip has the fingers fully flexed to form a hook in the palm. This is useful when precision is not a requirement and where power needs to be exerted over longer periods such as holding a suitcase or a shopping bag (Figure 4d).

\section{Basic Requirements for Hand Exoskeletons}

What is a hand exoskeleton? Hand exoskeletons are wearable robotic devices that have the aim of assisting the fingers, of the human hand, to complete its range of motion (ROM), amplify power, rehabilitating impaired hands or in today's society gives haptic feedback for virtual or teleoperation applications. The word "exoskeleton" actually refers to the hardouter shell of certain animals that serves the purpose of protecting and supporting their body. We as humans have endoskeletons that are located inside the body [31]. Therefore, the robotic devices up to this stage were designed to be fitted on the dorsal, palmar, or lateral side of the hand/fingers.

Certain requirements need to be kept in mind upon designing an exoskeleton, whether it is for assistive, rehabilitative, augmentative, or haptic purposes (Figure 5). Each class of exoskeleton has over the years defined certain requirements to suit their purpose. 


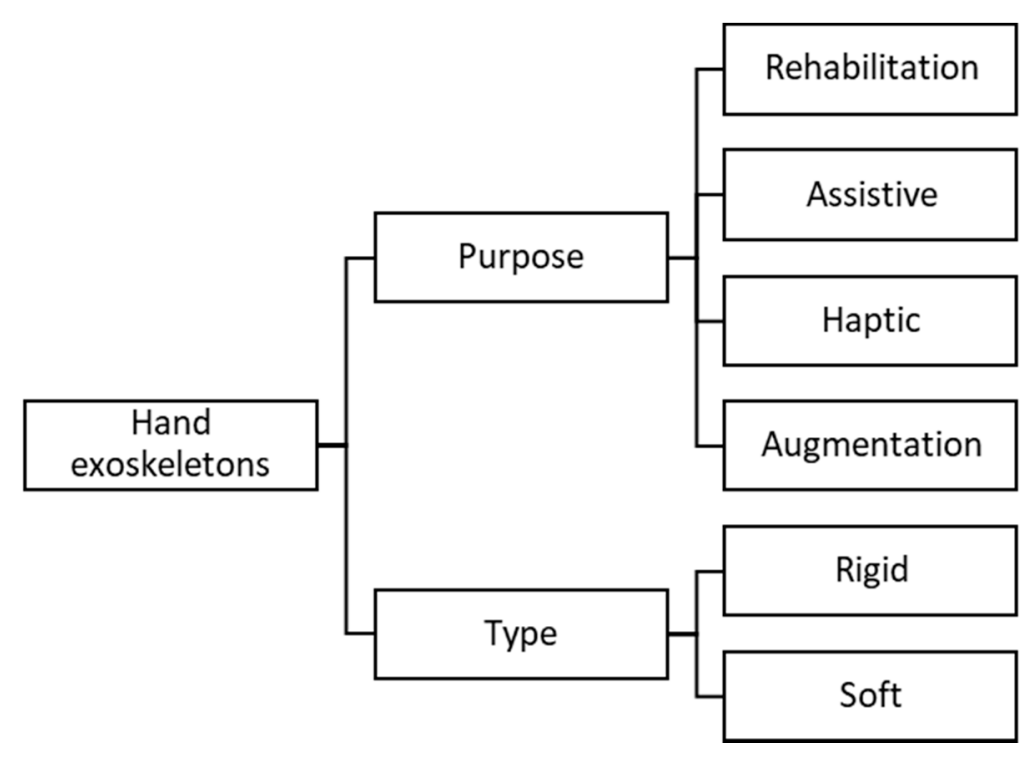

Figure 5. This diagram is an outline of the hierarchy structure identified for the various types of hand exoskeletons, in different fields, as well as the type of existing hand exoskeleton technologies.

There are mainly two types of hand exoskeletons developed over the years, which are classified as rigid and soft exoskeletons (Figure 5) or a combination of the two. Rigid exoskeletons are mechanisms where the force or torques are transmitted to the required joints through a mechanical structure. To ensure that the exoskeleton joints are aligned with the finger joints, ideally, the mechanical structure aligns with each joint (usually on the lateral side of the fingers) (Figure 6a). This can be considered to be the most intuitive design method, but it restricts the size due to the space between the fingers, and custom fits are usually required. This method is also known as the matched axis design [32,33]. Many exoskeletons were designed to reduce the size and add more DOF for the hand, which led to the remote center of rotation design [34] (Figure 6b). This design is usually fitted on the dorsal side of the fingers and transmits the forces to the joints through the phalanges. The bar mechanisms include parallelogram mechanisms and circular-prismatic joints [35-38]. Another design created over the years is mechanisms using four-bar linkages or other mechanisms to actuate the joints. These mechanisms also attach to the phalanges after the required joint and are usually a bit larger than the remote center of rotation mechanisms. These are also known as redundant linkages [39-42] (Figure 6c). A mechanism known as the base to distal topology (Figure 6d) has also been explored. This mechanism has only one contact point with the finger, usually the distal phalange or proximal phalange, and is coupled together through linkages connected in series. This design has the advantage of actuating several joints at the same time with less active control over each joint. This design is commonly referred to as the base-to-distal mechanism $[43,44]$ and is also mostly found at assistive-related exoskeletons.

One of the predicted future trend exoskeleton designs is known as compliant systems or "soft" hand exoskeletons. These systems are designed in the form of a glove with flexible materials or elastic structures to transmit the forces to the joints of the fingers. Many avenues have been and are still being explored such as artificial muscles [45], tendon-driven devices (Figure 6e) [46-49], and pneumatically actuated jointless structures (Figure 6f) [50-54]. These devices can be lightweight and compact at the hand but usually require cables or air tubes situated remotely to the actuating unit. Special design care must be taken, especially for rehabilitation and assistance purposes, because there is no rigid structure to guide the finger and transmit the required torques to the joint. The flexible structure usually relies on the rigid skeleton bone structure to guide the fingers in flexion and extension or abduction and adduction motions. Therefore, any misaligned forces may cause secondary injuries over time or cause discomfort to the users. 


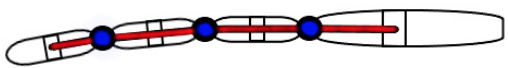

(a)

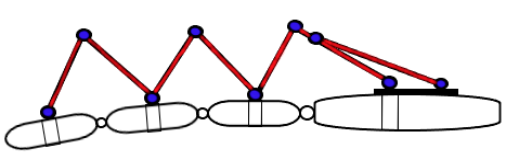

(c)

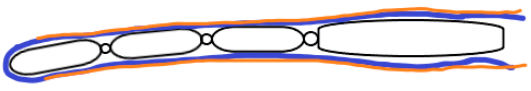

(e)

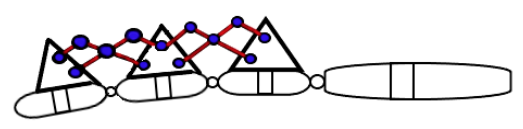

(b)

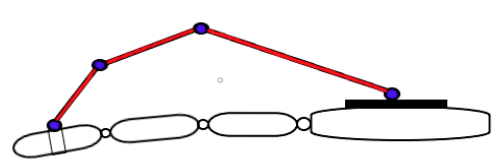

(d)

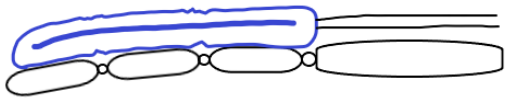

(f)

Figure 6. Different existing hand exoskeleton designs. Various designs exist for each category, although the fundamental design idea is illustrated. (a) Matched-axis design. (b) Remote center of rotation (RCR) design. (c) Redundant mechanism (four-bar link mechanisms). (d) Base-to-distal design. (e) Tendon driven glove (complaint). The tendon/cables are illustrated in orange, and the blue represents a glove or flexible base structure. (f) Jointless structure. Can either be actuated from compressed air (pneumatics) or hydraulic fluids.

There was a study done in 2018 by [55] to determine the design requirements for hand assistive powered exoskeletons. This study interviewed clinicians and patients with hand impairments to determine the most suitable requirements for an assistive hand exoskeleton. The clinicians emphasized the importance of obtaining opposition with the thumb and how it will increase the patient's ability to become more independent. The patients indicated the tasks that they would like the hand exoskeletons to assist them with such as hold utensils to eat, write, carry a bag, drink something, use a computer, etc. (many referring to pinch, power, and hook grip formations); there are many tasks identified through the interviews, which all are basic and everyday tasks. Many have indicated that the hand exoskeleton must at least be strong enough to hold a $750 \mathrm{~mL}$ can or mug and operate the device continuously for at least $6 \mathrm{~h}$. Patients also indicated that a weight of $200 \mathrm{~g}$ on the hand will be manageable, and an open palm would be preferred. Figure 7 indicates the average weight of each exoskeleton design type and can be compared to the preferred weight mentioned above.

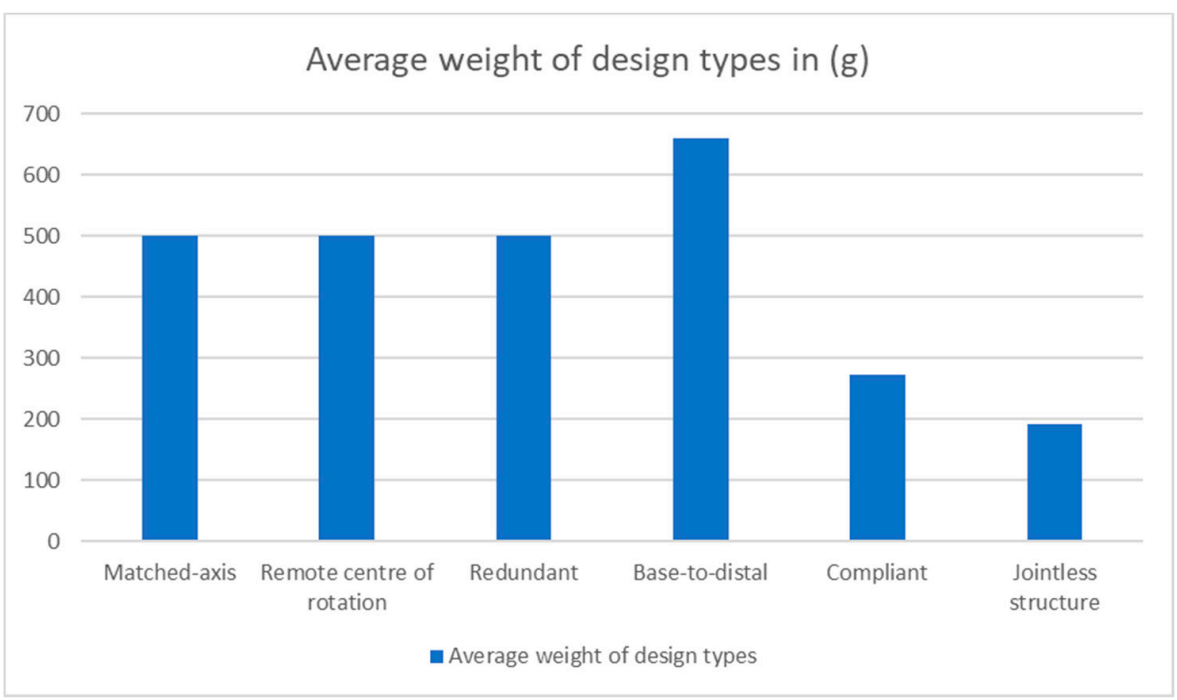

Figure 7. This graph shows the average weight of each exoskeleton design type by only considering the weight of the exoskeleton on the hand. 
This is a very useful paper to gather firsthand information on the possible end-user and determining the desired requirements to fulfill.

\subsection{General Requirements}

\subsubsection{Safety}

Safety is the most crucial requirement for all hand exoskeletons and exoskeletons in general, especially for active systems. These systems can cause harm to the user; therefore, caution must be taken when designing such a mechanism. The mechanical actuation and control system must ensure that the natural movements of the fingers are executed and do not induce secondary injuries to the users, especially for rehabilitation and assistive mechanisms. Mechanical stops, force limits, or limited rotation can be used for such systems to ensure that there will be no excessive range of motion movements. Designs incorporating such safety mechanisms are $[12,32,33,35-37,39-42,44,45,50,51,53,54,56-70]$.

\subsubsection{Comfort}

Hand exoskeleton must be comfortable for the user, especially for rehabilitation, assistive, and haptic devices. These devices are made to be worn for long periods. The hand exoskeleton is required to have an ergonomic structure and fit the hand to perform tasks. Soft exoskeletons are generally classified as more comfortable than rigid systems but can introduce discomfort when in operation if the forces are not transmitted correctly.

The interaction between the hand and the device is the most important aspect for comfort. Devices that utilize the construction of remote center of rotation, redundant, and base-to-distal generally have the interaction of the device with the respective phalanges of the fingers on the dorsal (backside) of the finger. Foam pads and Velcro or silicone straps are the most popular method for securing these devices to the fingers [12,35,38-41,43,58,59,61,63,71,72]. The foam acts as a damper and increases the comfort for the user. Some redundant devices are attached to a material glove such as in $[42,64]$, while other base-to-distal devices such as $[44,56]$ have custom-made thimbles to comfortably fit the user's fingertip. Compliant and jointless structures mostly use gloves as the interaction point between the fingers and the tendons or artificial muscles. This is one main reason for the higher comfort in "soft" exoskeletons due to the lack of "rigid" structures.

Most devices are in the prototyping phase, and generally, the "rigid" structures are constructed from polylactic acid (PLA) polymer, which is biodegradable and is generally used in $3 \mathrm{D}$ printing. The minority devices that were released for clinical environments are constructed from aluminum metal for durability [35]. "Soft" exoskeletons are generally made from soft materials such as silicone to reduce weight and increase comfort for the users.

\subsubsection{Affordability}

Hand exoskeletons and exoskeletons in general tend to be very expensive. This is due to the technology and materials available as well as this being a relatively new area of research. The development of technology as the field progresses makes the devices more affordable in today's society. Rapid prototyping such as 3D printing and software modeling enables devices to be made relatively efficient and cost-effective, but there is still a search for a design to accommodate all requirements with the best execution. The devices must be affordable to the patient and the clinicians if it is to be used in a clinical setting. Devices custom-designed for a patient are generally more expensive than a device that is transparent to various users. Low maintenance and ease of use is also generally a kind of mandatory requirement.

\subsubsection{Adaptability}

The devices are preferable to be designed for multiple end-users and to fit various hand sizes. This is especially necessary for augmentation, haptic, and rehabilitation devices due to various users that will use the device each with a different hand structure and size. 
The hand exoskeletons reviewed in this paper have been designed for adult-size hands, and many can adjust to the varying sizes in this range (refer to Table 1). Sandoval-Gonzalez et al. conducted an anthropometric study of the hand to obtain an average hand size from the combination of males and females from the ages of 16 to 70 [63], for hand exoskeleton design. This can be a good reference for future designs. Figure 8 (along with Table 1), indicates the distribution of the design topologies found in the literature.

Table 1. Captures the interaction between the human and the device as well as indicating the adaptability of the reviewed devices.

\begin{tabular}{|c|c|c|c|}
\hline Design Type & Wearability & Adaptability & Devices \\
\hline Matched-axis & $\begin{array}{l}\text { The exoskeleton generally has } \\
\text { concave-shaped clips inlined } \\
\text { with foam, which attaches to } \\
\text { the finger phalange through } \\
\text { Velcro or silicone straps. } \\
\text { These clips are designed to fit } \\
\text { the finger ergonomics, hence } \\
\text { the concave shape. }\end{array}$ & $\begin{array}{l}\text { To adjust to different finger } \\
\text { sizes, these are generally } \\
\text { designed to have the proximal } \\
\text { and middle phalange clips to } \\
\text { slide in or out to align the } \\
\text { joint axis to the exoskeleton } \\
\text { axis. These are usually passive } \\
\text { prismatic joints. }\end{array}$ & {$[32,33]$} \\
\hline
\end{tabular}

These devices are similar in the way they attached to the fingers. Usually, the section attached to the phalange has a concave shape to the phalange and attaches to the finger through a Velcro or silicone strap. Some devices have custom rigid rings the

Remote centre of rotation redundant and Base-to-distal phalanges interact with, and others have thimbles for the distal phalanges. Some exoskeletons have their interaction points with the finger attached to a glove for a more comfortable and convenient fitting.

Most of the compliant devices use gloves to anchor the actuating mechanisms to the Compliant appropriate joints or phalanges. Others make use of a custom silicone-based sleeve that enables custom interactions with the finger.

Gloves are the most popular method for attaching jointless

Jointless structures structures or artificial muscles. Velcro is used to attach the actuating device to the glove.

Gloves are adjustable to only a certain hand size before a different glove is required. This is a common issue with compliant devices. Custom silicone-based designs can adjust to a greater number of hand sizes.

This method of actuation cannot generally adjust to various hand sizes and are usually custom made for the end-user.

$[12,35,37-44,56-$

$58,60,61,63,64,67,69,72-74]$

[46-49,66,75-78] of adjustable to various hand simply adjusting the drawback to the device using a glove will be that a different size glove has to be used to for different hand sizes. 


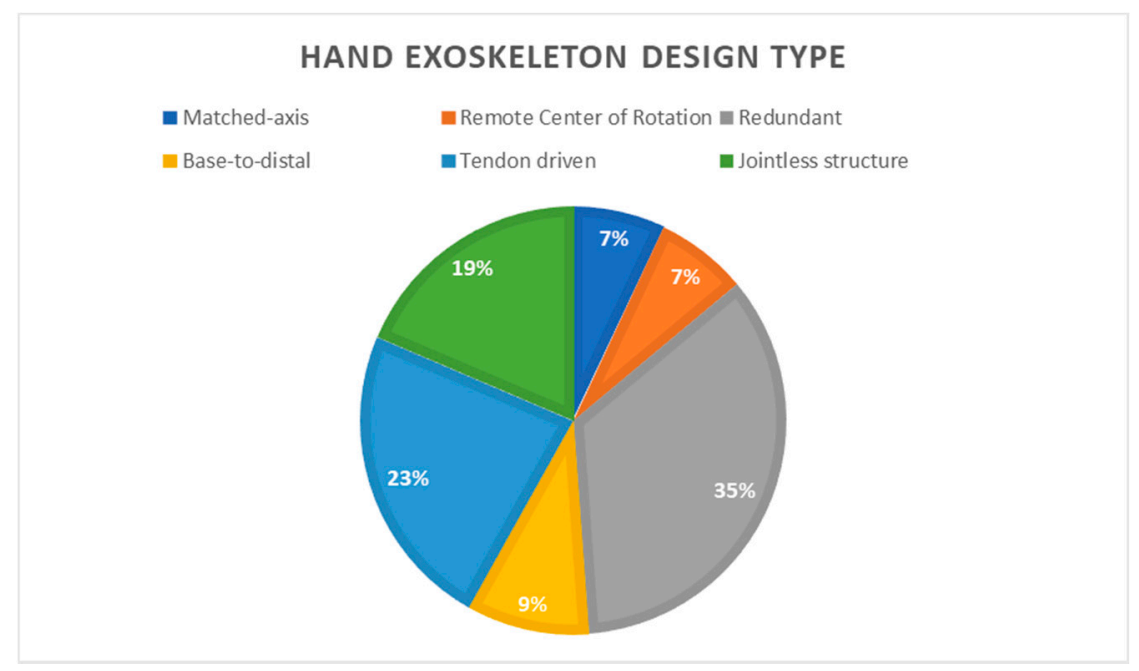

Figure 8. The pie chart indicates the distribution of the exoskeleton design type according to the literature.

\subsection{Specific Requirements}

As mentioned previously, there are multiple areas where the use of a hand exoskeletons can be beneficial, but the main focus is placed on rehabilitation and assistive devices.

\subsubsection{Rehabilitation}

These exoskeletons are designed to rehabilitate patients with disabilities and assist therapists to treat these patients. These devices are designed with the focus of executing repetitive actions and motions. This includes the flexion and extension of the fingers to mimic the activities of daily living or to execute continuous passive motion (CPM) for patients after surgery to prevent stiffness of the joints and tendons. These devices generally do not have to be portable due to it being used in a clinical or medical environment. It usually contains sensors for feedback to the therapists to track the patient's progress and to determine the severity of the impairment. These devices are mostly active devices with a relatively high output force projected to the patient's fingers depending on the training or rehabilitation given by the therapist as well as to overcome stiff joints if the patient suffers from that (Table 2).

\subsubsection{Assistive}

These types of exoskeletons are designed with the main purpose to assist the user to accomplish activities of daily living (ADL), such as making coffee, eating, holding a bag, etc. (refer to the interview conducted by [55] for more information). This type of hand exoskeleton is preferred to be portable, lightweight, easily wearable, and transparent, as the patient will operate this device in their home setting or a public area. The device is active and must allow a patient to interact with their environment actively. Sensory feedback information is not a requirement, but some devices have been designed to serve both rehabilitation and assistive purposes, which contains sensors for progress and finger tracking as well as force sensing for manipulating objects (Table 2).

\subsubsection{Haptic}

These types of exoskeletons are developed for healthy individuals with the main purpose to give haptic feedback for virtual and teleoperation applications. It allows the individual to interact with objects in the virtual environment and feel the objects through the exoskeleton. These devices are usually underactuated and contain sensors for finger tracking. The amount of output force to control the fingers is not as crucial as in other applications. Due to the device being worn by healthy individuals, adjustability 
is recommended for an affordable device, and individual finger movement is required (Table 2).

\subsubsection{Augmentation}

These types of hand exoskeletons serve the purpose to amplify the user's power. This is made for healthy individuals and portability is favorable. These types of exoskeletons are generally produced for military purposes, but it is also used in the space program to help astronauts flex and extend their fingers through the stiff spacesuit [80,81]. High power output is required for these types of hand exoskeletons with maximum safety precautions implemented, as these devices can cause serious harm to the user if malfunctioned (Table 2).

Table 2. These requirements are only the identified general important factors and may differ for certain applications.

\begin{tabular}{|c|c|}
\hline Type & Requirements \\
\hline Rehabilitation & $\begin{array}{c}\text { Safety } \\
\text { High output force } \\
\text { Transparent } \\
\text { Active or passive actuation } \\
\text { Easy wearable } \\
\text { Finger tracking/sensor feedback } \\
\text { Comfortable } \\
\text { Combined or independent finger control } \\
\text { Backdrivable }\end{array}$ \\
\hline Assistive & $\begin{array}{c}\text { Safety } \\
\text { Easy wearable } \\
\text { Transparent } \\
\text { Active actuation } \\
\text { Portable } \\
\text { Lightweight } \\
\text { Comfortable } \\
\text { Combined or independent finger control } \\
\text { Interaction with objects } \\
\text { Intention detection is preferable } \\
\text { Backdrivable } \\
\text { Affordable }\end{array}$ \\
\hline Haptic & $\begin{array}{c}\text { Safety } \\
\text { Transparent } \\
\text { Easy wearable } \\
\text { Portable } \\
\text { Lightweight } \\
\text { Independent finger movement } \\
\text { Finger tracking } \\
\text { Comfortable } \\
\text { Affordable }\end{array}$ \\
\hline Augmentation & $\begin{array}{c}\text { Safety } \\
\text { Easy wearable } \\
\text { Comfortable } \\
\text { Portable } \\
\text { Transparent } \\
\text { High output force }\end{array}$ \\
\hline
\end{tabular}

\section{Overview of Hand Exoskeleton Technologies}

By breaking down the various parts of the hand exoskeleton technologies, thus far, it is clear that it can be classified into sections of actuation, power transmission, sensing methods, and the control system methods used (Figure 9). 


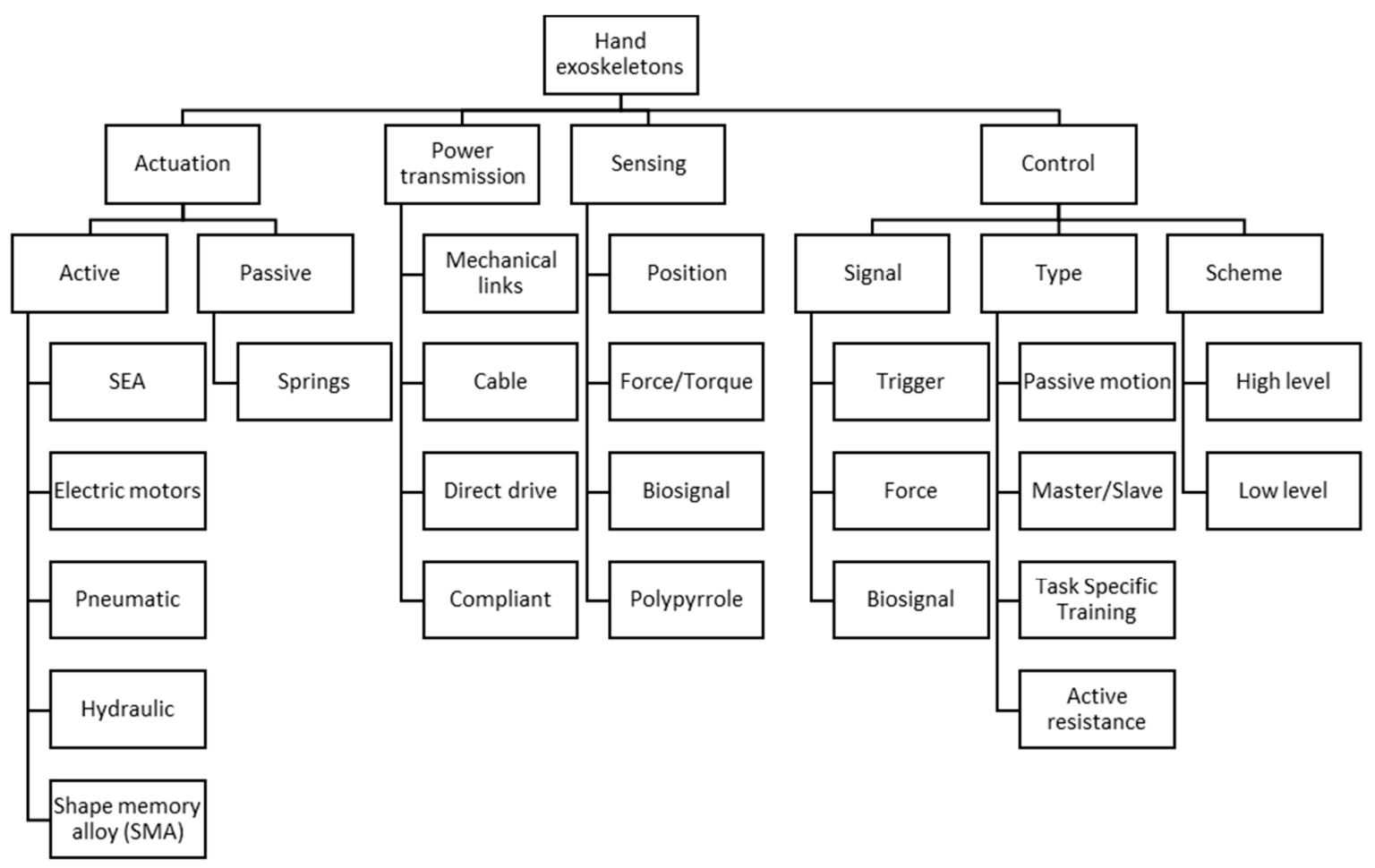

Figure 9. This diagram indicates the various elements, identified through previous designs, of the hand exoskeleton technologies and their basic building blocks. These various elements are still being researched and expanded for different applications and designs.

\subsection{Actuation}

Various actuating methods have been explored over the course and development of hand exoskeletons. Passive and active designs were created (Figure 10). These include restorative springs for a passive system, electric motors, pneumatics, Series Elastic Actuators (SEA), Shape Memory Alloys (SMA), and hydraulics for active systems. Each actuating method will be explained, and their characteristics are briefly summarized.

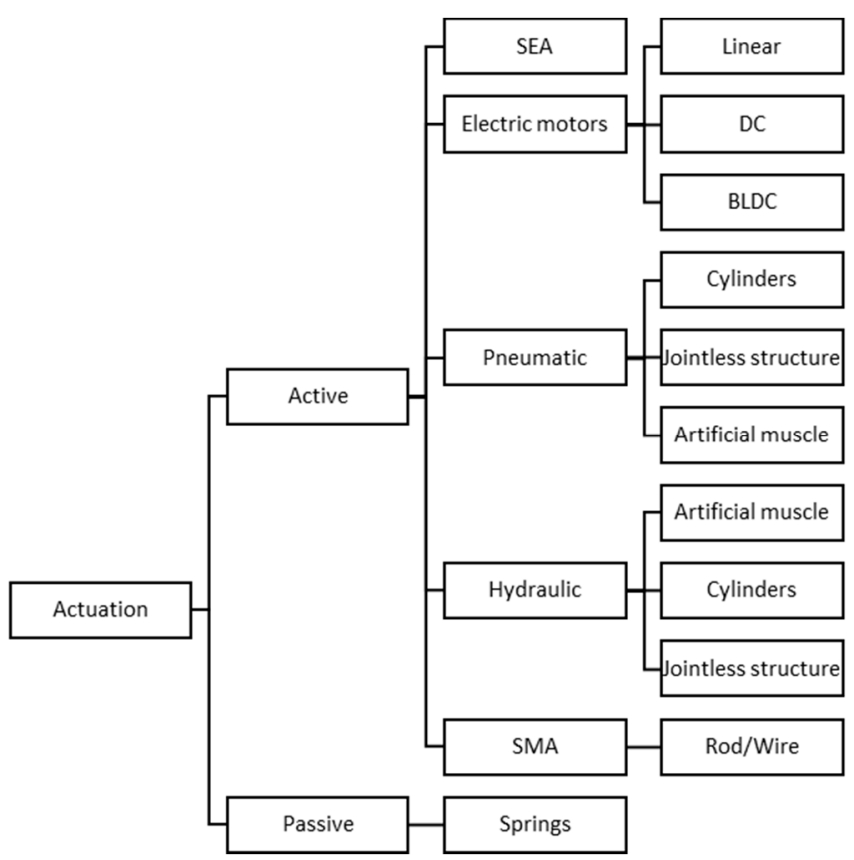

Figure 10. Illustrates the various actuation methods explored in both active and passive systems. 


\subsubsection{Passive Actuation}

A passive system generally includes parts that store potential energy (such as springs or any elastic material) and can operate without any electricity (Figure 10). These systems were designed for the main purpose to assist the patient in the last stages of training to strengthen their motor skills and the muscles of the impaired limb. These passive systems are made to be worn at home or any setting outside a clinical environment, but it can also be used in clinics or therapy offices. The SCRIPT passive orthosis (SPO) [82] is an example of such a system as well as SaeboGlove [83] and HandSOME [84]. SCRIPT and SaeboGlove are devices where individual finger movement can be accomplished, but the HandSOME device has been designed to combine the movement of the index, middle, ring, and little fingers, and the thumb is independent of the rest. This device allows the hand to accomplish the natural grasping motion and has been clinically tested.

\subsubsection{Active Actuation}

- Electric Motors: This is one of the most widely used and popular methods of actuating exoskeletons in general (Figure 11). There are many varieties found in the literature such as DC motors, Brushless DC (BLDC) motors, linear actuators, and servo motors (Figure 10). DC motors are known for their simplicity, easy to control, low cost, and backdrivability, but they suffer from high maintenance due to the wear of the brushes, in contact with the commutator, and low torque at high speeds. This requires the motor to be connected to a reduction (gears, pulleys, lead screws, etc.) unit to increase the torque, but this will reduce the operating speed of the motor. Devices such as $[31,32,38,41,43,44,47,48,56,57,59,61-63,65,69,70,74,85-87]$ all contain DC motors, and it includes servo motors. Servo motors are essentially geared DC motors with limited rotation, which are commonly driven by pulse width modulation (PWM) signals. The servomotors used in these hand exoskeleton prototyping are usually hobby-grade motors. Linear actuators are most of the time DC motors connected to a lead screw assembly to convert the rotational motion of the motor to linear motion. This motion is preferred in many rigid hand exoskeletons because the four-bar linkage system can be "pushed or pulled" to flex or extent the fingers as per the design and limits the ROM. This can be seen in devices such as [35,37,40,42,58,66-68,72]. BLDC is a motor that is part of the AC family (more specifically of a synchronous, permanent magnet type). It might not seem that way, but these types of motors are much better than DC motors regarding noise, size, efficiency, maintenance, etc. (Table 3), just to name a few. The BLDC motor uses an electronic inverter instead of a commutator and brushes to achieve rotation. Devices such as $[76,88]$ make use of the BLDC motor for actuation.

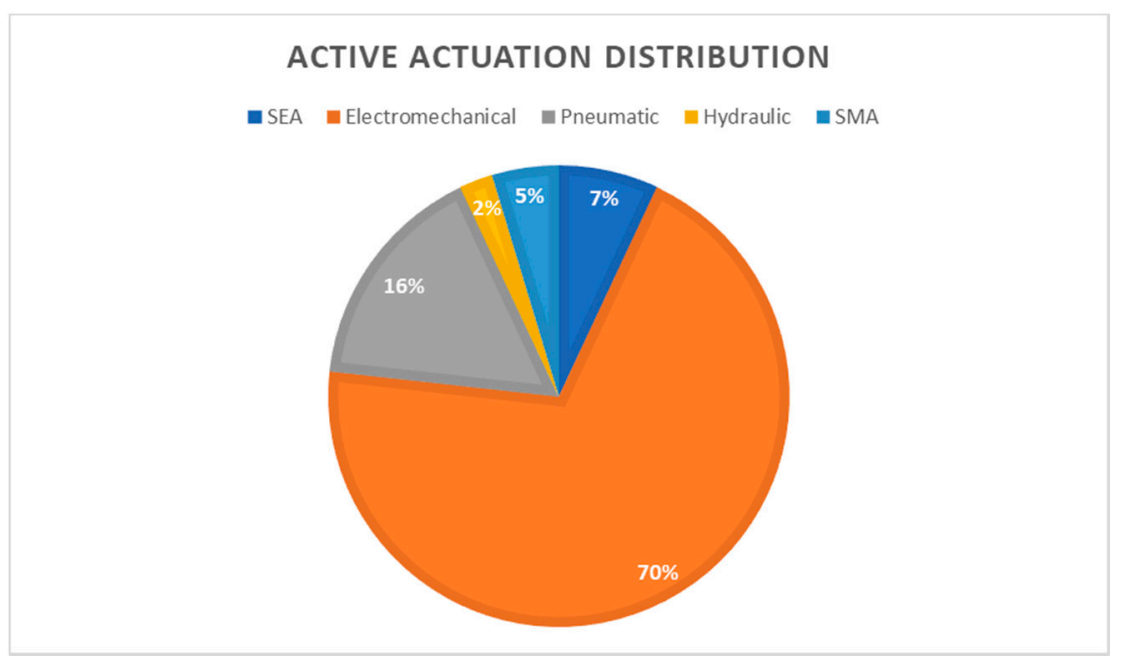

Figure 11. This chart indicates a distribution of the active actuation used in the literature. 
Table 3. Advantages and disadvantages of the various actuation methods. These are the basic identified parameters and may vary depending on the quality of the products used.

\begin{tabular}{|c|c|c|}
\hline Actuator Type & Advantage & Disadvantage \\
\hline DC Motor & $\begin{array}{c}\text { Low cost } \\
\text { High starting torque } \\
\text { Variable speed with voltage } \\
\text { Easy to control } \\
\text { Can switch rotation/Bidirectional }\end{array}$ & $\begin{array}{c}\text { High maintenance } \\
\text { Low torque at high speeds } \\
\text { Can spark on startup } \\
\text { Commutator cause power loss } \\
\text { Relatively noisy operation }\end{array}$ \\
\hline BLDC Motor & $\begin{array}{c}\text { High torque to weight ratio } \\
\text { Brushless } \\
\text { Better efficiency than DC motors } \\
\text { Low maintenance } \\
\text { Longer lifespan } \\
\text { Smaller in size than DC motors } \\
\text { Lower noise than DC motors } \\
\text { Suitable for medical applications } \\
\text { Can switch rotation/Bidirectional }\end{array}$ & $\begin{array}{c}\text { Higher cost than DC motors } \\
\text { Complex control } \\
\text { Resonance can be an issue }\end{array}$ \\
\hline Pneumatic & $\begin{array}{l}\text { High power to weight ratio } \\
\text { Easy to control } \\
\text { Cost-effective } \\
\text { Safe } \\
\text { Less moving parts }\end{array}$ & $\begin{array}{c}\text { Heavy and bulky } \\
\text { A leak can cause poor function } \\
\text { Temperature can affect the } \\
\text { system }\end{array}$ \\
\hline Hydraulic & $\begin{array}{l}\text { High power-to-weight ratio } \\
\text { Easy to control } \\
\text { Simple construction } \\
\text { Safe } \\
\text { Less moving parts }\end{array}$ & $\begin{array}{l}\text { Heavy and bulky } \\
\text { A leak can cause poor function } \\
\text { Dangerous if a pipe fails }\end{array}$ \\
\hline SEA & $\begin{array}{c}\text { Increase safety } \\
\text { Great shock absorbance } \\
\text { Lower reflected inertia } \\
\text { Accurate force measurement and } \\
\text { control }\end{array}$ & $\begin{array}{c}\text { Lower stiffness } \\
\text { Higher power requirement } \\
\text { Increase mechanical } \\
\text { complexity } \\
\text { Lower actuation bandwidth }\end{array}$ \\
\hline SMA & $\begin{array}{c}\text { High power-to-weight ratio } \\
\text { Lightweight }\end{array}$ & $\begin{array}{c}\text { Highly nonlinear } \\
\text { Saturated } \\
\text { Power loss in the form of heat } \\
\text { Complex control }\end{array}$ \\
\hline
\end{tabular}

- Pneumatic actuators: this method of actuating the fingers of the hand is the next most popular method of exploration (Figure 11). Pneumatic actuation refers to the use of compressed air to execute the required action. Various methods have been developed to acquire the ROM of the fingers by the use of inflatable flexible materials [51,52], pneumatic cylinders [60,89], bellow-shaped systems [53], or artificial muscles $[45,54,90]$. Some pneumatic cylinders are directly connected to the required phalanges. This means that these devices are usually situated in the palm as in [89], whereas most of the other systems are located at the dorsal side of the hand. Pneumatic systems are also used for augmentation purposes but work for rehabilitation and assistance as well. A pneumatic driven glove has the advantage of being lightweight on the hand itself as well as have a high power to weight ratio, but this system has a few drawbacks for use in assistive situations. Pneumatic systems require a compressor, storage tank, valves, transport air tubes, etc. This can cause the system to become bulky and heavy. According to Boser et al. [55], patients with hand impairments have indicated that a waist belt containing this equipment that weighs less than $3 \mathrm{~kg}$ will be acceptable, but in general, this equipment can be on the heavy side depending on the pressure and size required. Therefore, remote actuation is recommended for this actuator or with the use of a wheelchair where the equipment can be stored. 
- Hydraulic actuators: This method of actuation is similar to the pneumatic system in operation, but instead of air, an incompressible liquid is used. This is for applications where generally more power is required; therefore, it is suitable for use in augmentation devices. Hydraulic cylinders [60], flexible inflatable materials [50], as well as certain artificial muscles [45,54] are devices that are explored to transfer hydraulic power.

- Series Elastic Actuators (SEA): SEA is a system that can be driven by an electric motor but utilizes a spring element in series with the load, which creates certain unique features. The traditional aim of joints is to be as stiff as possible, but in the case of SEAs, the aim is to reduce the stiffness of the joint, which creates new possibilities. SEAs offer several advantages such as greater shock absorbance, lower reflected inertia, more accurate and stable force control, and the most important one is the increase in safety due to the lower stiffness [90]. This actuator seems to be an ideal solution for hand exoskeletons, but the reduction in joint or actuator stiffness means that lower forces can be transferred to the exoskeleton. It also increases the mechanical complexity of the device, has higher power requirements, and has a low actuation bandwidth. Very few researchers have implemented this type of actuator over the years such as $[42,61,65,69]$.

- Shape Memory Alloy (SMA): This type of actuator was explored by $[39,49]$. It is an unusual type of actuator, which works on the principle of deformation of the material. The material expands and contracts due to heating and cooling at certain temperatures. The material is usually made of a rod or wire type and is heated by applying a current through it. The system is considered to be highly nonlinear and saturated but has a high power to weight ratio. The rods or wire also produce a lot of heat, and safety must be considered when this is to be used as a driving system for an exoskeleton.

- Other: There have been a few other actuators explored such as electroactive polymers and ultrasonic motors, which is an indication that the search for an ideal actuator is still being researched [91].

\subsection{Power Transmission}

The following are various methods that have been explored to transmit the power from the actuation unit to the required joints of the hand (Figure 12).

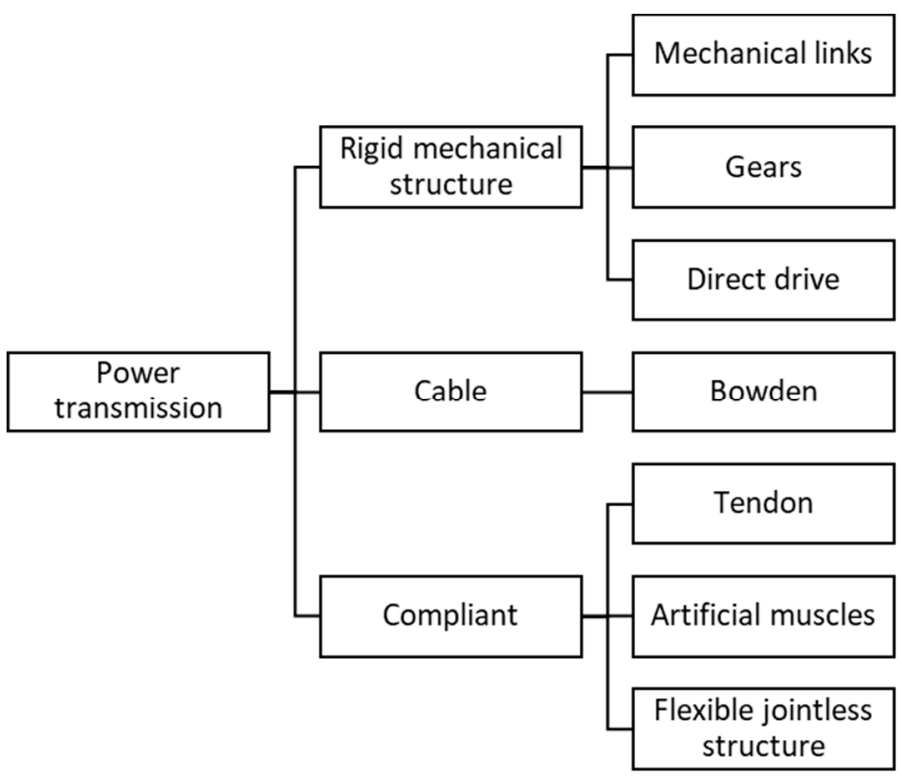

Figure 12. Illustrates the power transmission methods explored in different designs. 


\subsubsection{Rigid Mechanical Structure}

These transmission methods (Figure 12) are some of the first and most simple ways of transferring the actuator moves to the required joints. Direct drive is exactly what the word suggests; the motor is directly connected to the structure such as in $[43,44,56,63]$. There is a fine line between direct drive and a gear assembly. [43,44,56,63] are essentially also classified as a geared system, because the motor is connected through a gear train to the structure. A device such as [85] is also a good reference to a geared system. The idea behind a direct drive or geared system is for the actuators to be as close to the structure as possible, meaning that the motors are usually mounted on the dorsal side of the hand. This enables the devices to be portable and less complex as well as minimizes the power or transmission losses but increases the weight on the hand. Due to the mass issue and motor sizes, there are most of the time fewer actuators to actuate the fingers (this is called an underactuated system). Mostly all hand exoskeletons are underactuated due to the number of DOF and the required ROM the hand has to offer. It is merely impossible to fit each DOF with an actuator and maintain a portable system. Therefore, mechanical links were designed and implemented. These structures can actuate several DOF at the same time in a controlled manner by using one actuator depending on the design. The most popular devices are of the remote center of rotation [35,38] and four-bar linkage mechanisms [37,40-42,64,65,72]. Base-to-distal devices that have mechanical links in series are also popular if the device needs to fit various users and maintain a simple design [56,67,85,87]. Devices with a matched axis mechanical structure have also been explored such as $[31,32,62]$.

\subsubsection{Cable Mechanisms}

Cable mechanisms can be divided into Bowden cable driven devices and tendondriven devices (Figure 12), but tendon-driven systems are explained in the next section of "Compliant" mechanisms. Bowden cable transmission offers an alternative means of actuating the system through cables (or sometimes rigid rods), which are routed in a tube (usually from a material that offers low friction such as a Teflon tube or Polytetrafluoroethylene (PTFE) tube) to the actuating unit. This allows the actuating unit to be situated remotely from the hand exoskeleton itself. This system is usually used for stationary rehabilitation but can be situated in a wheelchair for mobility. Bowden cable transmission suffers greatly from friction, backlash, lower power transmission, due to the friction, and the sheaths exert forces on the exoskeleton when movement is applied, but inertia is reduced on the hand. This can be seen in devices such as $[32,57,59,61,66,69,70]$.

\subsubsection{Compliant Mechanisms}

Compliant structures generally refer to the category of "soft" exoskeletons. It can be divided into tendon-driven devices, artificial muscles, and flexible jointless structures (Figure 12).

- Power is transferred to the exoskeleton via tendon cables, but the difference between tendon and Bowden cable systems is that tendon cables mimic the hand anatomy structure by flexing and extending the fingers with a cable routed in a glove, whereas Bowden cables use a rigid structure to transfer the cable forces to the fingers, as mentioned previously. Tendon cables are usually connected to the distal part of the finger and flex or extend the finger by applying tension to the cable. This type of transmission is normally unidirectional, meaning only one cable can execute a single task such as flexion or extension. A second cable is required to have a bidirectional actuation, which means another actuator is generally required. These types of developed hand exoskeletons are usually underactuated systems where a single actuator can flex or extend multiple fingers such as in $[47,48,76]$ by the use of a single cable routed in a loop across or between the fingers. Other tendon-driven devices are usually driven by artificial muscles [45] or by SMA [49]. Tendon cables can suffer from cable breakage, the routing paths are sometimes complex and can cause power losses due to friction, but they can apply the required forces to the digit itself instead of the joints. 
- Artificial muscles are another compliant way of producing finger flexion and extension. This is usually driven through compressed air (pneumatics) or liquids (hydraulics) that are injected into a flexible material surrounded by a braided sheath that contracts when inflated and vice versa [50,54]. The most popular drawback to this design is known as ballooning, where the flexible material cannot bend anymore, and due to an increase in pressure of the fluid, the material blows up like a balloon. Methods have been implemented to overcome this effect, such as the type of braiding material used to restrict the flexible material movement.

- Another type of device that was developed, similar to an artificial muscle, does not require a braided sheath to create contraction or elongation. These are known as flexible jointless structures and are made from silicone rubber molded in a specific way to bend at certain sections when inflated. This can be seen in [51,52]. Another similar approach was taken by [53], but it created bellow-shaped sections at the joints for the bending and extending motions. A different approach was taken by $[58,66,68,70,86]$; these types made use of a thin spring metal plate that is compressed or tensioned to flex and extend the fingers, respectively. These structures are mainly custom-designed for a user, but due to the low cost of the rubber, it is not a great concern.

These types of power transmission devices are mostly situated on the dorsal side of the hand and the actuation unit remotely. Tendon-driven devices, as well as the compliant device using a thin spring metal for actuation, are best for flexion and extension of the fingers if actuated in both directions rather than artificial muscles and flexible jointless structures that can only be actuated in one direction, which is generally flexion. The extension is assisted by the stiffness of the material when air or liquid is exhausted. Figure 13, compiles the distribution of the various transmission methods found throughout the literature.

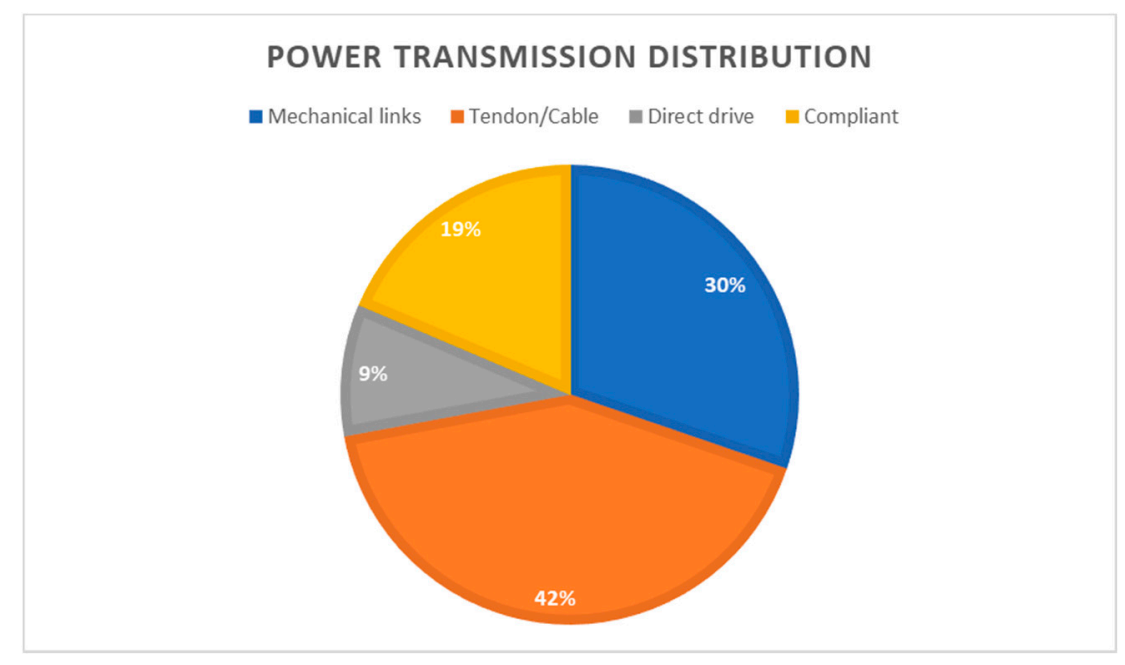

Figure 13. This chart indicates the distribution of the various power transmission methods found in the literature.

\subsection{Sensing}

Sensing refers to the use of sensors in the various exoskeletons to provide feedback to the control system as well as the user or therapist on progress or finger tracking. It is vital for active systems to have some sort of sensor to detect malfunctions or to limit the rotations of the fingers for safety reasons. For the system to function properly, the current state and desired states are measured by sensors. 


\subsubsection{Position}

In an active system especially for rehabilitation and haptic purposes, the position of the fingers in the current and desired state must be known. Then, this information can be reflected for the therapist on progress or live finger tracking for virtual or teleoperation applications. Various sensors have been used depending on the design and function of the device (Figure 14). Encoders such as optical or magnetic (hall-effect) encoders are generally used on the electric motors themselves to track the revolutions per minute (rpm) or position of the output device $[43,44,56,85]$. Potentiometers are the next most popular method of detecting a joint's position. These sensors are mostly mounted on the links $[43,57,59,74]$ connected to the joints of the fingers or on the lateral side [63] of the exoskeleton structure. Many systems also include servo motors in their designs, which contain potentiometers to detect the output angle $[41,62,87]$. Devices using linear actuation usually have a fixed finger position at a certain point on the linear axis; therefore, the potentiometer or hall sensors are mounted on the linear axis to determine the position of the output $[32,35,37,40,42,58,67,68,72]$. Flex/bend sensors are also used, but the accuracy may vary if the sensor shifts from the position; therefore, it is not the most popular sensor, but it is readily used in the master and slave control glove, as will be seen later $[48,51]$.

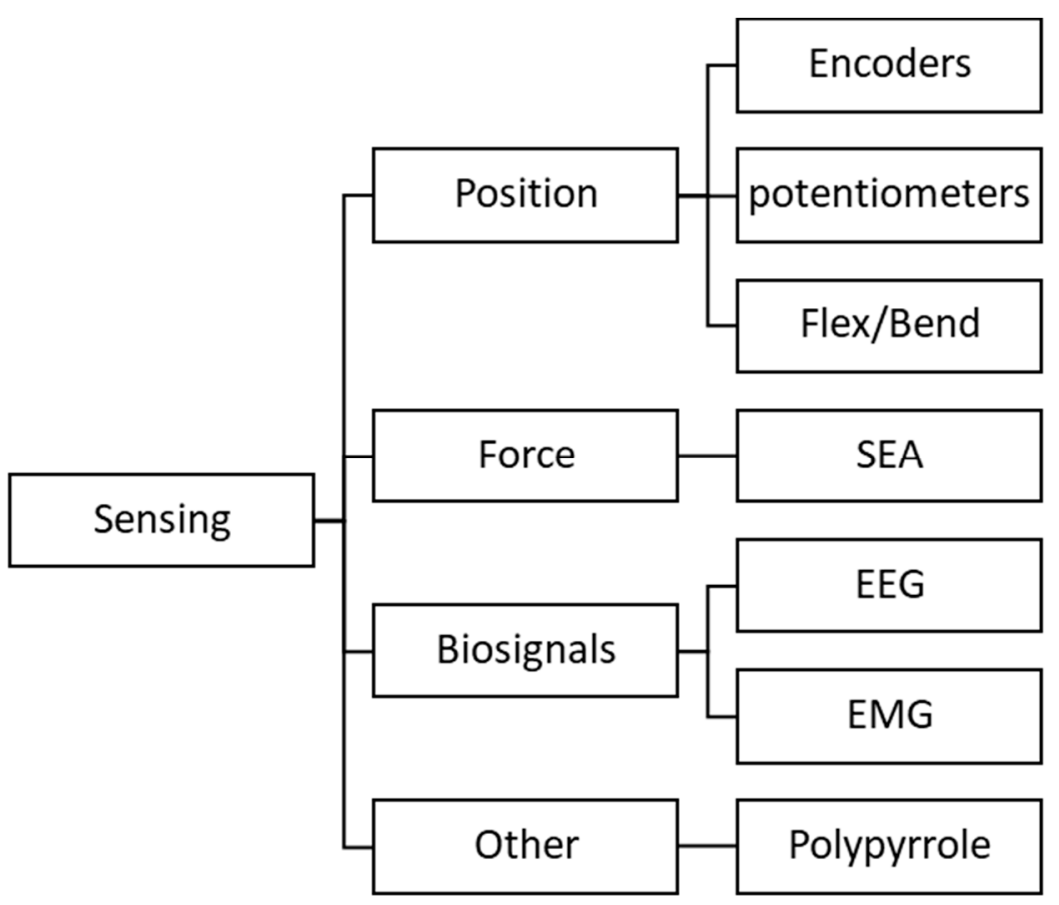

Figure 14. Illustrates the various sensing methods explored throughout hand exoskeletons.

\subsubsection{Force}

Force is also an important unit to measure, as your hands can obtain various grips and hold objects with various grip forces depending on the objects (fragile or strong). The force is generally sensed on the tip of the finger where force sensors are placed, due to the fingertip being the part of the finger that is always in contact with an object when it is held or manipulated. One major use for the force sensors is for feedback to the therapist to analyze the progress of the rehabilitation process. Devices such as $[32,40,43,57,59,60,71,73,77]$ indicate the applications of these force sensors. According to [20], the minimum required gripping force for manipulating objects are between $10 \mathrm{~N}$ and $-13 \mathrm{~N}$. Redundant, remote center of rotation, and base-to-distal devices apply their respective forces perpendicular to the contact points between the device and the phalanges. These forces can be nonuniform, depending on the number of active DOF, unlike pneumatically or hydraulically-driven jointless structures, the pressure is uniform across the actuator, which generates a uniform grip force that can be seen in the study performed by [52]. 


\subsubsection{Biosignals}

Biosignals are a way to detect the user's intentions by measuring electrical muscle activity in the forearm or motor functions in the brain. There are mostly two types of biosignals that are measured, not only for control but for sensing whether the hand is being active and to observe the recovery of certain motor and muscle functions. Surface electromyography (sEMG) can be used as a sensor to control the exoskeleton or observe and get feedback from the progress of training. sEMG is the measure of muscle electrical activity in the body. In the case of a hand, the muscles responsible for flexing and extending the fingers through tendons are located in the forearm. sEMG is used as a sensor to measure muscle activity to determine if the patient's muscles are recovering and strengthening. Challenges arising with sEMG are that the electrodes used to stick to the forearm must be placed in the same place for the best results. The electrodes can give distorted readings when they are applied to a hairy, dirty, or wet skin surface. The number of electrodes used is generally less than the number of DOF of the hand; therefore, it can be challenging to get independent high DOF measurements [54,60,64,70,72].

Another biosignal that is used for determining the progress of the rehabilitating patient is the use of an electroencephalogram (EEG). The brain is active with electrical activity when certain muscles are actuated, in this case, the hand. An EEG can be used to measure these electrical signals and determine if the muscle motor function is recovering from the impairment in the case of rehabilitation for a patient with impaired hands. EEG can be both invasive and noninvasive, but most of the devices are utilizing the noninvasive EEG in the form of a head cap full of electrodes $[66,68]$. EEG signals are known to have low signal to noise ratios and must be amplified and filtered to obtain a working signal. EEGs also have longer reaction times, and significant signal processing is required.

\subsubsection{Other}

One study in particular [45] used a unique method for a sensor that is known as a polypyrrole sensor. The principle of this type of sensor is to pass a current through a conductive polymer and measure the conductivity of the material. The conductivity changes as the material is deformed, and therefore, the strain can be determined. This sensor offers good stability, easy and cheap manufacturing, and is light in weight. The downside to this sensor is that it utilizes a lot of wiring and can become bulky as the number of sensors increases.

Most of the pneumatic-driven soft exoskeletons control their system through the help of pressure sensors. The devices are usually designed to have a certain finger bending curvature at a certain pressure; therefore, pressure sensors are utilized in those exoskeletons.

\subsection{Control}

The control of the exoskeleton refers to the brains of the operation. The control usually consists of a microcontroller to process the sensor information and to give commands to the actuation units. A processing unit, such as a computer, is also used to further process the sensor data and give feedback to the therapist on the progress of the patient or for the signal processing when user intention is detected for active control.

The control can be divided into the control signals, the type of control for a specific task or rehabilitation exercise, and the control scheme to process the information and task executions (Figure 15). 


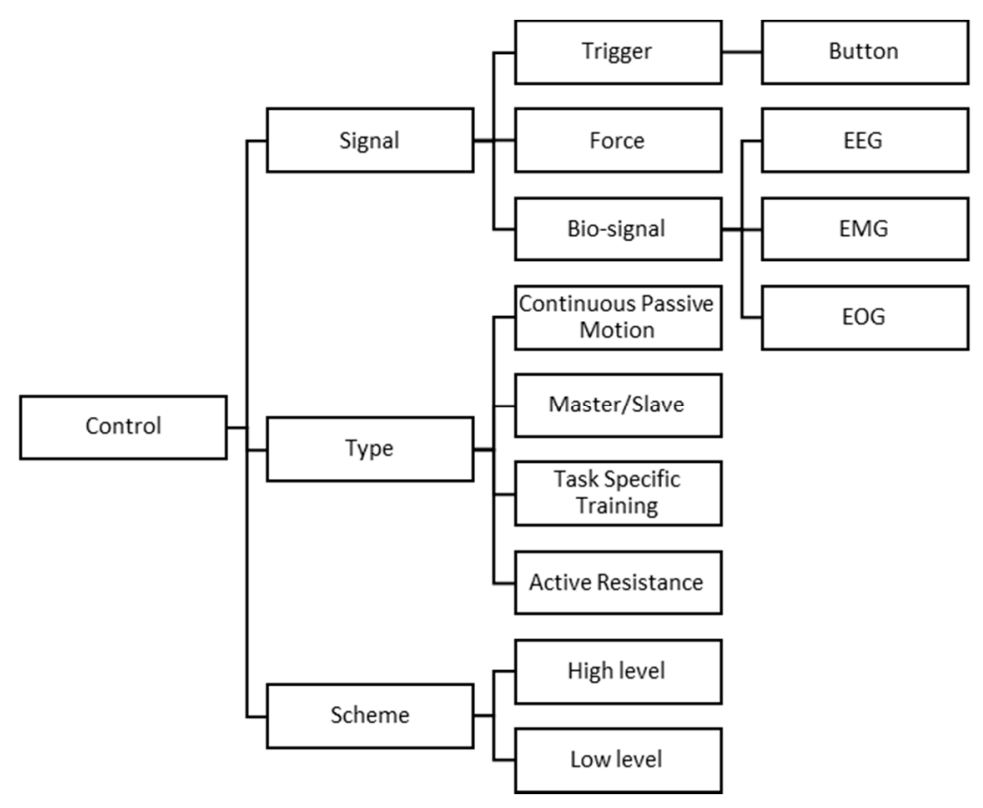

Figure 15. Illustrates the various control signals, type of control, as well as control schemes explored in various design attempts.

\subsubsection{Signals}

There are mainly three types of control signals that have been implemented in various exoskeletons, such as a trigger, force, and bio-signal control. Table 4 , summarizes these control signals.

Table 4. This table is a summary of the control signals for exoskeletons and indicates the identified advantages and disadvantages of these methods to obtain the signals.

\begin{tabular}{|c|c|c|c|}
\hline Signals & Description & Advantages & Disadvantages \\
\hline Trigger & $\begin{array}{l}\text { An electrical switch } \\
\text { can determine the } \\
\text { output action or can } \\
\text { switch through } \\
\text { various modes of } \\
\text { action. }\end{array}$ & $\begin{array}{c}\text { The most basic } \\
\text { control structure and } \\
\text { is reliable. }\end{array}$ & $\begin{array}{l}\text { The other hand or } \\
\text { someone is usually } \\
\text { required to operate } \\
\text { the switches. }\end{array}$ \\
\hline Force & $\begin{array}{l}\text { The output force on } \\
\text { the fingertips is } \\
\text { measured to execute } \\
\text { hand movements or } \\
\text { grip objects. }\end{array}$ & $\begin{array}{l}\text { The user can adjust } \\
\text { the required force. }\end{array}$ & $\begin{array}{l}\text { Usually, a force input } \\
\text { is required and } \\
\text { sometimes is not } \\
\text { possible for paralyzed } \\
\text { patients. }\end{array}$ \\
\hline EEG & $\begin{array}{l}\text { The electrical brain } \\
\text { activity is measured } \\
\text { to identify the user's } \\
\text { intention and to } \\
\text { actuate the } \\
\text { exoskeleton } \\
\text { accordingly. }\end{array}$ & $\begin{array}{l}\text { Users with severe } \\
\text { muscle paralysis can } \\
\text { actuate their limbs } \\
\text { through a BCI. }\end{array}$ & $\begin{array}{c}\text { EEG signals are prone } \\
\text { to noise and have a } \\
\text { low signal to noise } \\
\text { ratio. }\end{array}$ \\
\hline EMG & $\begin{array}{l}\text { Measure the electrical } \\
\text { muscle activity for } \\
\text { user intention } \\
\text { detection through } \\
\text { electrodes placed on } \\
\text { the muscle. }\end{array}$ & $\begin{array}{l}\text { Reliable control can } \\
\text { be and various hand } \\
\text { motions executed. }\end{array}$ & $\begin{array}{l}\text { The electrodes must } \\
\text { be placed in the same } \\
\text { place for the accuracy } \\
\text { and repeatability of } \\
\text { tasks and free of dirt, } \\
\text { hair, and sweat. }\end{array}$ \\
\hline
\end{tabular}


Trigger

The trigger refers to buttons that the user must press to execute a certain task, such as closing the hand to grab an object or to open the hand for release [32]. Electrical switches have also been used to select the type of training for the user or therapist to select.

Force

Force signal control is more of an interactive mode of control for the user. This is one of the more popular methods of control and sensing (Figure 16). The hand exoskeleton is actuated according to the force applied by the user. As mentioned previously, the force sensors are usually mounted on the fingertips. This signal can allow the user to train at their limits for rehabilitation tasks [42,60,77], but it is also mainly used in assistive and augmentation exoskeletons to assist the user in manipulating objects and enhance their grip force, respectively.

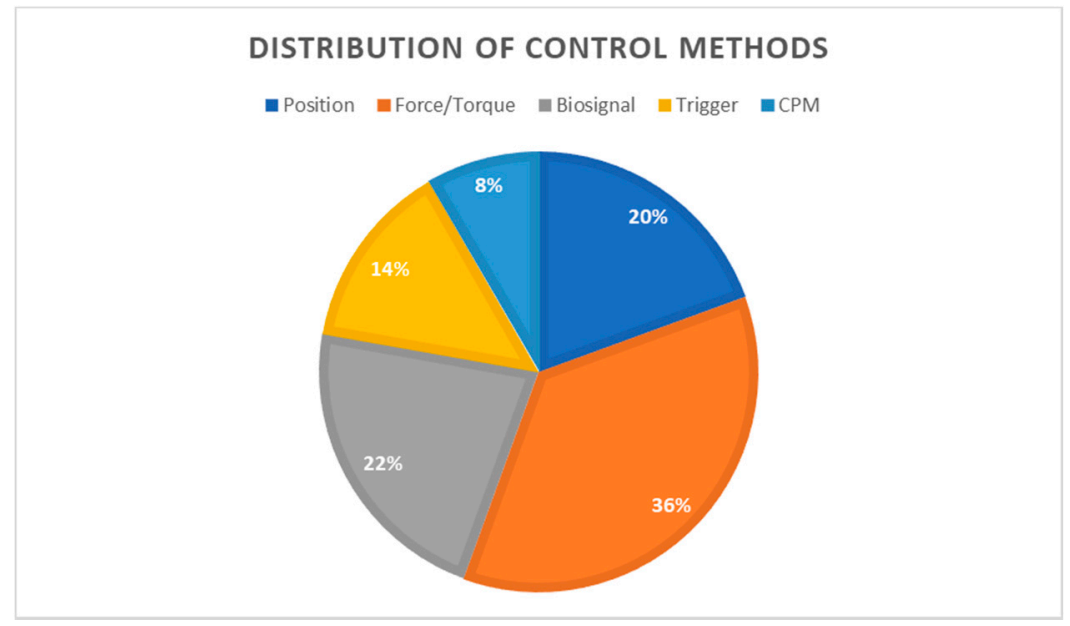

Figure 16. This chart shows the distribution of the control methods used in various designs.

\section{Biosignal}

The current popular area of research is biosignal control of hand exoskeletons and exoskeletons in general. The most popular signals are mostly EEG, electromyography (EMG), and electrooculography (EOG). These signals can all be obtained through a noninvasive process and let the user constantly interact with the device. The main use for these signals is to sense the intentions of the user and apply the specified action to the exoskeleton. It has been shown that the user's interaction with the training can improve their recovery and strengthen their cognitive function [58].

- EEG: The brain sends electrical pulses to the specific muscles through nerves. These nerves carry the information to activate the specified muscle. To keep the human in control of the hand exoskeleton, an EEG can be used to measure the electrical brain activity. This electrical brain activity can be processed through a brain-computer interface $(\mathrm{BCI})$ to communicate to the hand exoskeleton. This method is especially used when the user has a severe impairment, which therefore bypasses the electrical pulses to the muscles through the nerves via the BCI. Then, the BCI sends commands to the control unit of the hand exoskeleton, and tasks are executed according to the signal. The noninvasive EEG method consists of an electrode cap that is mounted on the head of the user.

- EMG: The muscles, when active, generate electrical signals that can be measured. The EMG is applied to the required area on the forearm via surface electrodes. These electrodes can measure the activity level of electrical muscle intensiveness. This control signal can be processed through various machine learning algorithms to obtain the specified threshold for certain actions to be executed. 
- EOG: The EOG signal is the measure of the cornea-retina standing potential that is active between the back and front of the human eye. This signal is generally combined with the EEG signals to execute certain tasks.

\subsubsection{Type}

Different types of controls have been explored with certain designs (Table 5), many targeting specific areas of rehabilitation, and others for assisting purposes (Figure 15). Many of these control techniques are also commonly referred to as the types of rehabilitation training methods, but some are also used for assistive purposes.

Table 5. This table gives information about rehabilitation type of exoskeletons used to treat different injuries or diseases.

\begin{tabular}{|c|c|c|}
\hline Device & Design and Actuator Type & Injury or Disease \\
\hline$[46,49,66,75]$ & $\begin{array}{c}\text { Compliant, } \\
\text { tendon-driven/Bowden cable }\end{array}$ & $\begin{array}{c}\text { Cerebral vascular disease } \\
\text { (Stroke) }\end{array}$ \\
\hline$[35,38]$ & $\begin{array}{c}\text { Remote center of rotation } \\
\text { (metal links with polymer } \\
\text { splint), linear actuators }\end{array}$ & $\begin{array}{c}\text { Cerebral vascular disease } \\
\text { (Stroke) }\end{array}$ \\
\hline$[31-33,88]$ & $\begin{array}{c}\text { Matched-axis (phalange } \\
\text { segment shells), Bowden cable } \\
\text { transmission }\end{array}$ & $\begin{array}{l}\text { Cerebral vascular disease } \\
\text { (Stroke)/ Hemiparalysis }\end{array}$ \\
\hline [12] & $\begin{array}{l}\text { Redundant (four-bar linkage), } \\
\text { gear train electric motors }\end{array}$ & $\begin{array}{c}\text { Cerebral vascular disease } \\
\text { (Stroke) }\end{array}$ \\
\hline$[57,61,64,69,73]$ & $\begin{array}{l}\text { Redundant, Bowden cable } \\
\text { transmission }\end{array}$ & $\begin{array}{c}\text { Cerebral vascular disease } \\
\text { (Stroke) }\end{array}$ \\
\hline$[37,40,58,67,77]$ & Redundant, linear actuator & $\begin{array}{l}\text { Cerebral vascular disease } \\
\text { (Stroke)/ Grip pathologies }\end{array}$ \\
\hline [39] & $\begin{array}{l}\text { Redundant (Links), shape } \\
\text { memory alloy }\end{array}$ & $\mathrm{CPM}$ \\
\hline [43] & Base-to-distal, direct drive & $\begin{array}{c}\text { Cerebral vascular disease } \\
\text { (Stroke) }\end{array}$ \\
\hline [50] & $\begin{array}{c}\text { Jointless flexible structure, } \\
\text { hydraulic }\end{array}$ & Grip pathologies \\
\hline$[51,53]$ & $\begin{array}{l}\text { Jointless flexible structure, } \\
\text { pneumatic }\end{array}$ & $\begin{array}{l}\text { Cerebral vascular disease } \\
\text { (Stroke)/Arthritis/CPM }\end{array}$ \\
\hline [63] & Redundant, direct drive & $\begin{array}{c}\text { Cerebral vascular disease } \\
\text { (Stroke)/ CPM }\end{array}$ \\
\hline$[68,78]$ & Compliant, linear actuator & $\begin{array}{c}\text { Cerebral vascular disease } \\
\text { (Stroke) }\end{array}$ \\
\hline
\end{tabular}

- Continuous Passive Motion (CPM): This method ignores the intentions of the user and only actuates the exoskeleton along a predefined trajectory path. There is usually no feedback to the user on progress or such because this mode of control is used for patients right after hand surgery or the initial stages of an injury to prevent the development of stiffness.

- Master/Slave: This technique requires a control glove and the exoskeleton glove. The control glove usually consists of sensors that are used as input or control signals for the exoskeleton. The control glove essentially controls the movements of the exoskeleton; in other words, the exoskeleton mimics the motions of the control glove. This technique is used for rehabilitation purposes to keep the patient in the loop of control by interacting with the device. Two hands are usually required for operation: 
one healthy hand to rehabilitate the impaired hand. This method is recommended for patients with hemiplegia.

- Task-Specific Training: This is a type of training method that allows the patient to be active in the rehabilitation process by executing certain tasks with the exoskeleton provided by the therapist, such as picking and placing objects. This type of control is more of a training technique for rehabilitation but utilizes either a Master/Slave or bio-signal control for the main operation.

- Active resistance: This is another type of rehabilitation technique to improve the disability of the patient. The technique allows the exoskeleton to resist the motion of the patient by a set resistance parameter depending on the patient's progress. Force control is a popular method for measuring and resisting the user's motions.

\subsubsection{Scheme}

There are mainly two types of control schemes utilized by exoskeletons, which are known as low-level and high-level control, respectively.

- Low-level control: This type of control can be referred to as the actuator drivers or the scheme that processes the information given by the high-level controller. This level of control is the most used due to its simplicity and reliability. The low-level control essentially captures all the sensor information and acts according to its specifications.

- High-level control: This control has a higher level on the hierarchy, which in turn gives it its name. This scheme involves the processing of information and determining the commands sent to the low-level controller to execute the tasks. Processes that involve high-level control usually consider factors such as position, force, impedance, or admittance. EEG or EMG signal processing has a form of high-level control to detect the intention of the user and act according to the classifications. Position estimation or path planning are also good examples. These systems are usually also referred to as intelligent.

\section{Existing Hand Exoskeletons}

This section contains a summary of existing active hand exoskeletons found in the literature. There exist several designs, which all contain some sort of key design features to improve the technology. The review done on these designs is to underline key design features and limitations. Both rigid and soft hand exoskeletons are mentioned as well as their intended applications and contributions. Not all the designs are listed below; refer to Table 6 for a summary of the designs and specifications reviewed.

\subsection{Mohamaddan et al.}

The study includes the development of a wire-driven hand rehabilitation device, by [75], to flex and extend the fingers of post-stroke patients, especially focusing on patients with paralysis on one side of the body (hemiplegia).

The proposed concept utilizes a cable for the extension of the finger and a cable for the flexion. The extension cable is situated on the dorsal side of the finger, which only connects to the distal part of the finger. The flexion cable is situated on the lower side (ventral) of the finger with a connection point also on the distal part of the finger. The authors are using the finger bone structure as the guideline for the range of motion. This actuating method flexes the distal joint (DIP) first, then the PIP joint, and lastly the MCP joint. This is not the natural flexion and extension motions of the fingers, as explained in [46].

The hand is activated through the cables connected to a gearbox driven with a DC motor. The device is self-controlled, meaning that it has a controller to actuate the flexion and extension movements and can be controlled with the patient's other hand. The controller is essentially a trigger system with electrical switches to execute certain commands such as flexion and extension. 
Table 6. Summary of rehabilitation, assistive, haptic, and augmentation hand exoskeletons with their mechanical and control design attributes in chronological order.

\begin{tabular}{|c|c|c|c|c|c|c|c|c|c|c|c|c|}
\hline Reference & Year & $\begin{array}{l}\text { Device } \\
\text { Name }\end{array}$ & Function & Actuation & $\begin{array}{l}\text { Design } \\
\text { Topology }\end{array}$ & $\begin{array}{l}\text { Degrees of } \\
\text { Freedom }\end{array}$ & $\begin{array}{l}\text { Force/Torque/ } \\
\text { Pressure Output } \\
\text { (N/Nm/Pa) }\end{array}$ & $\begin{array}{l}\text { Finger- } \\
\text { Assisted } \\
\text { Motion }\end{array}$ & Weight & Portability & $\begin{array}{l}\text { Control } \\
\text { Signals }\end{array}$ & Adaptability \\
\hline [75] & 2010 & $\begin{array}{l}\text { Mohamaddan } \\
\text { et al. }\end{array}$ & Rehabilitation & Tendon/Cable & Compliant & - & - & Flex/Extend & - & No & $\begin{array}{l}\text { Switch } \\
\text { trigger }\end{array}$ & No \\
\hline [35] & 2010 & Tong et al. & Rehabilitation & Linear actuator & $\begin{array}{l}\text { Remote } \\
\text { center of } \\
\text { rotation }\end{array}$ & 10 & - & Flex/Extend & $500 \mathrm{~g}$ & Yes & EMG & Yes \\
\hline [32] & 2010 & HANDEXOS & Rehabilitation & Bowden cable & Matched axis & $\begin{array}{c}3 \text { active } \\
3 \text { passive }\end{array}$ & - & $\begin{array}{l}\text { Flex/Extend } \\
\text { Ab/Add }\end{array}$ & - & Yes & $\begin{array}{l}\text { Switch } \\
\text { trigger }\end{array}$ & Yes \\
\hline [12] & 2010 & HEXORR & Rehabilitation & Four-bar linkage & Redundant & 2 & - & $\begin{array}{l}\text { Flex/Extend } \\
\text { Ab/Add } \\
\text { (+Thumb) }\end{array}$ & - & No & $\begin{array}{l}\text { Torque } \\
\text { control }\end{array}$ & Yes \\
\hline [76] & 2011 & In et al. & Assistance & Tendon/Cable & Compliant & - & $18 \mathrm{~N}$ & Flex/Extend & $80 \mathrm{~g}$ & Yes & - & - \\
\hline [56] & 2011 & HEXOSYS-II & Assistance & Direct drive & Base to distal & 5 & - & Flex/Extend & $\pm 500 \mathrm{~g}$ & Yes & - & Yes \\
\hline$[57,73]$ & 2011 & iHandRehab & $\begin{array}{c}\text { Rehabilitation/ } \\
\text { Haptic }\end{array}$ & Bowden cable & Redundant & 8 & - & $\begin{array}{l}\text { Flex/Extend } \\
\text { (+Thumb) } \\
\text { Ab/Add } \\
\text { (+Thumb) }\end{array}$ & $250 \mathrm{~g}$ & No & $\begin{array}{l}\text { Torque } \\
\text { control }\end{array}$ & Yes \\
\hline [77] & 2012 & SEM glove & Rehabilitation & $\begin{array}{c}\text { Bowden cable } \\
\text { (Underactuated) }\end{array}$ & Compliant & - & $3-4 \mathrm{~N}$ & Flex/Extend & $700 \mathrm{~g}$ & Yes & $\begin{array}{l}\text { Force } \\
\text { control }\end{array}$ & No \\
\hline [45] & 2013 & UoA & $\begin{array}{l}\text { Rehabilitation/ } \\
\text { Assistance }\end{array}$ & $\begin{array}{l}\text { Pneumatic/Tendon } \\
\text { cable }\end{array}$ & $\begin{array}{l}\text { Artificial } \\
\text { muscle }\end{array}$ & 19 & - & Flex/Extend & $<1 \mathrm{~kg}$ & Yes & Position/Force & Yes \\
\hline [39] & 2013 & Tang et al. & Rehabilitation & $\begin{array}{c}\text { Shape memory } \\
\text { alloy } \\
\text { (Underactuated) }\end{array}$ & Redundant & 5 & $20 \mathrm{~N}$ & Flex/Extend & - & Yes & EMG & Yes \\
\hline$[31,33]$ & 2013 & HX & Rehabilitation & $\begin{array}{l}\text { Bowden cable } \\
\text { (Underactuated) }\end{array}$ & Matched axis & $\begin{array}{l}3 \text { active } \\
6 \text { passive }\end{array}$ & $\mathrm{DIP}-0.25 \mathrm{Nm}$ & $\begin{array}{c}\text { Flex/Extend } \\
\text { Free } \\
\text { Ab/Add }\end{array}$ & $\begin{array}{l}500 \mathrm{~g} \text { hand, } \\
1 \mathrm{~kg} \\
\text { actuation }\end{array}$ & Yes & - & Yes \\
\hline [59] & 2013 & Zhang et al. & Rehabilitation & Bowden cable & $\begin{array}{l}\text { Circuitous } \\
\text { joint }\end{array}$ & 6 & - & Flex/Extend & - & No & - & Yes \\
\hline [40] & 2013 & $\begin{array}{l}\text { Lambercy } \\
\text { et al. }\end{array}$ & Rehabilitation & $\begin{array}{c}\text { Linear } \\
\text { actuator/Four- } \\
\text { bar } \\
\text { linkage }\end{array}$ & Redundant & $\begin{array}{l}1 \text { active } \\
3 \text { passive }\end{array}$ & $10 \mathrm{~N}$ & $\begin{array}{l}\text { Thumb } \\
\text { opposition }\end{array}$ & $150 \mathrm{~g}$ & Yes & $\begin{array}{l}\text { Position } \\
\text { control }\end{array}$ & Yes \\
\hline
\end{tabular}


Table 6. Cont.

\begin{tabular}{|c|c|c|c|c|c|c|c|c|c|c|c|c|}
\hline Reference & Year & $\begin{array}{l}\text { Device } \\
\text { Name }\end{array}$ & Function & Actuation & $\begin{array}{l}\text { Design } \\
\text { Topology }\end{array}$ & $\begin{array}{l}\text { Degrees of } \\
\text { Freedom }\end{array}$ & $\begin{array}{l}\text { Force/Torque/ } \\
\text { Pressure Output } \\
\text { (N/Nm/Pa) }\end{array}$ & $\begin{array}{l}\text { Finger- } \\
\text { Assisted } \\
\text { Motion }\end{array}$ & Weight & Portability & $\begin{array}{l}\text { Control } \\
\text { Signals }\end{array}$ & Adaptability \\
\hline [88] & 2013 & Wei et al. & Rehabilitation & Cable & Matched axis & 1 & - & Flex/Extend & - & Yes & EMG & Yes \\
\hline [60] & 2014 & OFX & Augmentation & Pneumatic & Redundant & 2 & $42.3 \mathrm{~N}$ & Flex/Extend & - & No & $\begin{array}{l}\text { Force } \\
\text { control }\end{array}$ & Yes \\
\hline [74] & 2014 & RML glove & Haptic & Cable & Base to distal & - & $10 \mathrm{~N}$ & $\begin{array}{l}\text { Resistive } \\
\text { force }\end{array}$ & $180 \mathrm{~g}$ & Yes & $\begin{array}{c}\text { Force } \\
\text { input, } \\
\text { Potision } \\
\text { output }\end{array}$ & Yes \\
\hline [50] & 2014 & $\begin{array}{l}\text { Polygerinos } \\
\text { et al. }\end{array}$ & $\begin{array}{l}\text { Rehabilitation/ } \\
\text { Assistance }\end{array}$ & Hydraulic & $\begin{array}{l}\text { Jointless } \\
\text { flexible } \\
\text { structure }\end{array}$ & - & $8 \mathrm{~N}$ & Flex/Extend & $\begin{array}{l}285 \mathrm{~g} \text { hand, } \\
3.3 \mathrm{~kg} \\
\text { actuation }\end{array}$ & Yes & - & - \\
\hline [46] & 2015 & Yang et al. & Rehabilitation & Tendon/cable & Compliant & 3 & $14.7 \mathrm{~N}$ & Flex/Extend & - & Yes & - & No \\
\hline [51] & 2015 & ExoGlove & $\begin{array}{l}\text { Rehabilitation/ } \\
\text { Assistance }\end{array}$ & Pneumatic & $\begin{array}{l}\text { Jointless } \\
\text { flexible } \\
\text { structure }\end{array}$ & 12 & $3.59 \mathrm{~N}$ & Flex/Extend & $200 \mathrm{~g}$ hand & Yes & - & No \\
\hline [47] & 2015 & Exo-Glove & Assistance & $\begin{array}{c}\text { Tendon/cable } \\
\text { (Underactuated) }\end{array}$ & Complaint & - & $40 \mathrm{~N}$ & Flex/Extend & $194 \mathrm{~g}$ hand & Yes & $\begin{array}{l}\text { Wrist } \\
\text { motion }\end{array}$ & No \\
\hline [37] & 2015 & Cui et al. & Rehabilitation & $\begin{array}{l}\text { Linear actua- } \\
\text { tor/Linkage }\end{array}$ & Redundant & 5 & - & Flex/Extend & - & Yes & - & Yes \\
\hline [52] & 2016 & Yap et al. & Assistance & Pneumatic & $\begin{array}{l}\text { Jointless } \\
\text { flexible } \\
\text { structure }\end{array}$ & 15 & $13.6 \mathrm{~N}$ at $153 \mathrm{kPa}$ & Flex/Extend & $170 \mathrm{~g}$ hand & Yes & EMG/RFID & No \\
\hline [41] & 2016 & HES & Assistance & Cable/Linkage & Redundant & 4 & $10 \mathrm{~N}$ & Extend & $350 \mathrm{~g}$ & Yes & $\begin{array}{l}\text { Switch } \\
\text { trigger }\end{array}$ & Yes \\
\hline [42] & 2016 & Jo et al. & Haptic & $\begin{array}{l}\text { Linear actua- } \\
\text { tor/Linkage/SEA }\end{array}$ & Redundant & 3 & $3 \mathrm{~N}$ & Flex/Extend & $298 \mathrm{~g}$ & Yes & $\begin{array}{l}\text { Force } \\
\text { control }\end{array}$ & Yes \\
\hline [53] & 2016 & $\begin{array}{l}\text { Haghshenas- } \\
\text { Jaryani } \\
\text { et al. }\end{array}$ & Rehabilitation & Pneumatic & $\begin{array}{l}\text { Soft-Rigid } \\
\text { hybrid }\end{array}$ & 15 & - & Flex/Extend & - & No & $\mathrm{CPM}$ & No \\
\hline
\end{tabular}


Table 6. Cont.

\begin{tabular}{|c|c|c|c|c|c|c|c|c|c|c|c|c|}
\hline Reference & Year & $\begin{array}{l}\text { Device } \\
\text { Name }\end{array}$ & Function & Actuation & $\begin{array}{l}\text { Design } \\
\text { Topology }\end{array}$ & $\begin{array}{l}\text { Degrees of } \\
\text { Freedom }\end{array}$ & $\begin{array}{l}\text { Force/Torque/ } \\
\text { Pressure Output } \\
\text { (N/Nm/Pa) }\end{array}$ & $\begin{array}{l}\text { Finger- } \\
\text { Assisted } \\
\text { Motion }\end{array}$ & Weight & Portability & $\begin{array}{l}\text { Control } \\
\text { Signals }\end{array}$ & Adaptability \\
\hline [44] & 2016 & HEXOTRAC & Haptic & $\begin{array}{c}\text { Direct drive } \\
\text { (Underactuated) }\end{array}$ & Base to distal & 6 & $4.8 \mathrm{~N}$ & $\begin{array}{l}\text { Resistive } \\
\text { force }\end{array}$ & - & Yes & $\begin{array}{l}\text { Force } \\
\text { control }\end{array}$ & Yes \\
\hline [48] & 2016 & Popov et al. & Assistance & Tendon/cable & Compliant & - & $16 \mathrm{~N}$ & Flex/Extend & $340 \mathrm{~g}$ & Yes & - & Yes \\
\hline [63] & 2016 & ExoK'ab & Rehabilitation & Direct drive & Redundant & 30 & - & Flex/Extend & - & Yes & $\begin{array}{l}\text { Position/ } \\
\text { Force } \\
\text { control }\end{array}$ & Yes \\
\hline [79] & 2017 & Yap et al. & Assistance & Pneumatic & $\begin{array}{l}\text { Jointless } \\
\text { flexible } \\
\text { structure }\end{array}$ & 15 & $9.12 \mathrm{~N}$ at $120 \mathrm{kPa}$ & Flex/Extend & $\begin{array}{l}180 \mathrm{~g} \text { hand, } \\
1.26 \mathrm{~kg} \\
\text { actuation }\end{array}$ & Yes & $\begin{array}{c}\text { Pressure } \\
\text { control }\end{array}$ & Yes \\
\hline [49] & 2018 & $\begin{array}{l}\text { Kazeminasab } \\
\text { et al. }\end{array}$ & $\begin{array}{l}\text { Rehabilitation/ } \\
\text { Assistance }\end{array}$ & $\begin{array}{c}\text { Tendon } \\
\text { cable/SMA } \\
\text { (Underactuated) }\end{array}$ & Compliant & 5 & $45 \mathrm{~N}$ & Flex/Extend & $\begin{array}{l}85 \mathrm{~g} \text { hand, } \\
517 \mathrm{~g} \\
\text { actuation }\end{array}$ & Yes & $\begin{array}{l}\text { Force } \\
\text { control }\end{array}$ & No \\
\hline [54] & 2018 & $\begin{array}{l}\text { Al-Fahaam } \\
\text { et al. }\end{array}$ & Augmentation & Pneumatic & $\begin{array}{l}\text { Artificial } \\
\text { muscle }\end{array}$ & 15 & $25 \mathrm{~N}$ & Flex/Extend & $120 \mathrm{~g}$ hand & No & $\begin{array}{l}\text { Position/ } \\
\text { Force } \\
\text { control }\end{array}$ & No \\
\hline [38] & 2018 & ReHand & Rehabilitation & $\begin{array}{c}\mathrm{DC} \\
\text { motor/Sliding } \\
\text { linkage }\end{array}$ & $\begin{array}{l}\text { Remote } \\
\text { Center of } \\
\text { rotation }\end{array}$ & 10 & - & Flex/Extend & - & Yes & $\begin{array}{l}\text { EMG/ } \\
\text { Voice } \\
\text { control }\end{array}$ & Yes \\
\hline [67] & 2019 & Jo et al. & Rehabilitation & $\begin{array}{l}\text { Linear actuator/ } \\
\text { linkage }\end{array}$ & Redundant & 1 & - & Flex/Extend & $156 \mathrm{~g}$ & Yes & СРM & Yes \\
\hline [72] & 2019 & Akgun et al. & Rehabilitation & $\begin{array}{l}\text { Linear actua- } \\
\text { tor/Linkage }\end{array}$ & Redundant & 1 & $45 \mathrm{~N}$ & Flex/Extend & - & Yes & $\begin{array}{l}\text { Adaptive } \\
\text { compli- } \\
\text { ance }\end{array}$ & Yes \\
\hline [68] & 2019 & Li et al. & $\begin{array}{l}\text { Rehabilitation/ } \\
\text { Assistance }\end{array}$ & $\begin{array}{c}\text { Linear } \\
\text { actuator/Spring } \\
\text { link }\end{array}$ & $\begin{array}{l}\text { Soft-Rigid } \\
\text { hybrid }\end{array}$ & 5 & $7.3 \mathrm{~N}$ & Flex/Extend & $401 \mathrm{~g}$ & Yes & EEG & No \\
\hline [69] & 2019 & $H X-\beta$ & Rehabilitation & $\begin{array}{c}\text { Bowden } \\
\text { cable/SEA } \\
\text { (Underactuation) }\end{array}$ & Redundant & 5 & $4 \mathrm{~N}$ & Flex/Extend & $420 \mathrm{~g}$ & No & $\begin{array}{l}\text { Position/ } \\
\text { Torque } \\
\text { control }\end{array}$ & Yes \\
\hline
\end{tabular}


Table 6. Cont.

\begin{tabular}{|c|c|c|c|c|c|c|c|c|c|c|c|c|}
\hline Reference & Year & $\begin{array}{l}\text { Device } \\
\text { Name }\end{array}$ & Function & Actuation & $\begin{array}{l}\text { Design } \\
\text { Topology }\end{array}$ & $\begin{array}{l}\text { Degrees of } \\
\text { Freedom }\end{array}$ & $\begin{array}{l}\text { Force/Torque/ } \\
\text { Pressure Output } \\
\text { (N/Nm/Pa) }\end{array}$ & $\begin{array}{l}\text { Finger- } \\
\text { Assisted } \\
\text { Motion }\end{array}$ & Weight & Portability & $\begin{array}{l}\text { Control } \\
\text { Signals }\end{array}$ & Adaptability \\
\hline$[70]$ & 2020 & $\begin{array}{l}\text { RELab } \\
\text { tenoexo }\end{array}$ & Assistance & $\begin{array}{c}\text { Bowden } \\
\text { cable/Spring link } \\
\text { (Underactuated) }\end{array}$ & $\begin{array}{l}\text { Soft-Rigid } \\
\text { hybrid }\end{array}$ & 3 & $6.4 \mathrm{~N}$ & $\begin{array}{l}\text { Flex/Extend } \\
\text { Ab/Add }\end{array}$ & $\begin{array}{l}148 \mathrm{~g} \text { hand, } \\
492 \mathrm{~g} \\
\text { actuation }\end{array}$ & Yes & EMG & Yes \\
\hline [78] & 2020 & Serbest et al. & Rehabilitation & $\begin{array}{c}\text { Linear } \\
\text { actuator/Tendon } \\
\text { cable/Springs }\end{array}$ & Compliant & 1 & $6 \mathrm{~N}$ & Flex/Extend & $750 \mathrm{~g}$ & Yes & - & Yes \\
\hline
\end{tabular}


Problems such as cable tension, shifting of finger clips, and complexity arise during the experimental phase of concept 1 . In concept 2, the finger clips were limited to four only, one on each middle phalange (because testing indicated it to be the best place for pulling the finger), the device had two separate controllers: one for the thumb and another for the other fingers. The main problem encountered was the control of the thumb due to its structure. The final design consists of a combination of the mechanical supporting structure and the cable actuation. One wire is used to flex all four fingers, and individual cables are used to extend each finger individually. The thumb has its own set of cables. A cotton glove was introduced to improve the comfort of the device in contact with the hand.

The device is controlled with a push-button controller. It is mainly focused on rehabilitation (not a portable device) of flexion, extension, fist making, and grasping exercises.

\subsection{Tong et al.}

This design introduces a hand exoskeleton capable of actuating all five fingers with two DOF (flexion and extension) for each finger [35]. The hand is controlled through the patient's intentions by using EMG signals.

The purpose of designing such a hand exoskeleton was to improve the quality and activities of daily living for individuals with hand disabilities, meaning that this device is focused on rehabilitation and assistance. This is due to the current devices not being portable.

The device is focused on task training, such as assisting opening and closing of the hand. It can perform continuous passive motion (CPM) as well as active control through EMG intention detection. Another requirement is that the user must be able to feel the objects with their hands; therefore, the palmar side must be free from any structure, forcing a dorsal fixture to be designed.

Regarding the actuation, the device was designed using a finger assembly that is underactuated and has one linear actuator for each finger. The MCP joint and the PIP joint have virtual centers of rotation (VCRs) and ROMs of $55^{\circ}$ and $65^{\circ}$, respectively. The linear actuator can exert a maximum force of $23 \mathrm{~N}$ at a speed of $12 \mathrm{~mm} / \mathrm{s}$. A full flexion or extension takes around $4 \mathrm{~s}$ to complete. The device weighs around $500 \mathrm{~g}$ and can be put on within $5 \mathrm{~min}$.

The thumb can only be flexed and extended and is held in a natural posture through a brace.

In addition, there is a wireless remote control with a Liquid Crystal Display (LCD) screen to assist therapists to actuate the device when necessary and to select the modes of operation.

A pilot study was done to validate the design. Two chronic subjects have undergone training sessions, and the muscle activity was recorded before and after the experiment. The study was done over 15 sessions for each patient. The results indicated improvements in the functionality of the hands. Both patients have improved their activities of daily life as they can pick up objects with their impaired hand as well as hold a pen and write a few words.

\subsection{HANDEXOS}

This paper introduces a novel multi-phalange finger hand exoskeleton for post-stroke rehabilitation named HANDEXOS [32].

The design of the hand exoskeleton consists of a shell-like structure on the phalanges to distribute the forces and for comfort. It utilizes the matched axis design strategy mentioned previously. The fingers are actuated remotely via Bowden cables to reduce the weight and inertia of the moving parts. The device has active and passive DOF such as flexion/extension and abduction/adduction and offers the full ROM of the finger.

Each finger has a module that consists of three links each with an upper and lower shell secured with a Velcro strap to the individual phalanges. The palmar shells house a force sensor on each shell for monitoring the contact forces. The links are joined together 
using active and passive DOF. The exoskeleton has three active and three passive DOF. The active DOFs actuate the MCP, PIP, and DIP joints, whereas one passive DOF is for the abduction/adduction of the MCP joint. Another is used between the MCP and PIP joint to adjust for finger lengths. The last passive DOF is on the middle shell to adjust the DIP joint for alignment.

The actuator is remotely placed and actuates the joints through cables. One cable is used for active extension of each finger, and three individual cables are used to passively flex the MCP, PIP, and DIP joints. The system is underactuated, meaning that the flexion motion is caused solely by compression springs, and the extension is controlled through a DC motor linear screw setup. The cables are fixed to pulleys on the lateral sides of the finger: one side for extension and the other for flexion. The design can be easily adjusted to various finger sizes and is made for post-stroke rehabilitation. The exoskeleton has a considerable number of sensors. There are three force sensors on the joints, an encoder on the motor axis, and hall sensors on the linear screw for limit switches.

The control system has a combination of high-level and low-level control.

\subsection{HEXORR}

The Hand Exoskeleton Rehabilitation Robot (HEXORR) [12] has been developed for the main purpose to rehabilitate an impaired hand, especially for patients suffering from hemiplegia. The hand exoskeleton (HE) can provide the active full range of motion for all the digits. The HE is designed to actuate digits $2-5$ together and the thumb separately. The design features a low friction gear train and electric motors that enable the device to measure both position and torque for various therapy control modes. It only consists of two actuators but has been designed to replicate the natural grasping motion of the hand. It can provide flexion/extension as well as abduction/adduction to the fingers and has a high degree of transparency. The device is meant for rehabilitation purposes only, which means it is a heavy and bulky design meant for stationary applications in a controlled environment. To accomplish the finger ROM, the design utilizes a four-bar linkage mechanism with the purpose to minimize backdrivability but features the matched axis design topology.

\subsection{In et al.}

This design features a soft jointless structure for assistive hand exoskeletons [76]. Assistive devices have the main requirement of being portable and lightweight; therefore, the focus of this design was to develop a device that has a jointless structure and is underactuated. This soft hand exoskeleton features a compliant tendon driven topology, where all three joints can be flexed by using only a single wire. The design is inspired by the biomechanics and anatomy of the hand. The wires are routed through tubes that are placed in such a position that it replicates the pulley structures for the finger tendons. The authors proposed a unique routing path to actuate the fingers through a single actuator. All of the wirings are routed in a wearable glove. The flexion motions are active (through a BLDC motor), and the extension motions are passive (through linear springs). The hand exoskeleton fingertip forces were measured to be $18 \mathrm{~N}$ with a tension force of $35 \mathrm{~N}$. The experiments validated the design, but it is clear that the efficiency of the device is quite low due to friction.

\section{6. iHandRehab}

This paper presents a cable-driven design of a thumb and index finger hand exoskeleton for rehabilitation and haptic feedback uses [57]. The exoskeleton is designed to actuate in both active and passive modes, has bidirectional movement, and has four DOF, which can be actuated individually.

The device contains sensors for force and position feedback. The actuation unit is mounted remotely from the body (desk mounted) and actuate the joints through cables. 
The control system utilizes high-level control, which is integrated with the virtual environment. The hand exoskeleton weighs about $250 \mathrm{~g}$ on the hand.

The authors used a parallelogram shape (Redundant topology) made from the links to flex and extend each joint. Each joint has a position sensor to capture the angle of that joint. To accommodate the various finger sizes, a slider mechanism between each joint was adopted and can be adjusted accordingly.

\subsection{Rahman et al.}

This paper presents the design of an exoskeleton to flex and extend the fingers by utilizing bilateral movement training [58]. The exoskeleton design features couplings attached to the finger phalanges. A flexible wire is attached to a linear actuator and the links on the phalanges. Flexion occurs if the linear actuator pushes on the rod and generates the bending force to flex the fingers and vice versa for the extension. The device is controlled through a master/slave system. This features a control glove that actuates the exoskeleton according to its motion. This is mainly intended for the patient to rehabilitating their hemiparetic hand and features the independent movement of all five fingers.

\subsection{SEM Glove}

The SEM glove [77] is a patented soft hand exoskeleton with the intention of grasp improvement and rehabilitation. The design features an underactuated tendon-driven glove that can assist a patient to manipulate objects. The actuation unit consists of a DC motor that is connected to a leadscrew and nut which in turn flex and extend the specified digits through a cable transmission. The glove only actuates the thumb, middle, and ring fingers through the actuating unit that is located in a wearable satchel on the patient's back. The glove features force sensors located in the tip of the fingers as well as capacitive sensors located in the palm. The glove utilizes high-level control strategies to accomplish the grasping motions.

\subsection{UoA Hand Exoskeleton}

This is a five-fingered hand exoskeleton [45] driven by pneumatically artificial muscles and features a unique approach to a strain sensor for rehabilitation and assistance applications. The requirements for this design were to feature a lightweight, low profile, and portable device. The design has 10 pneumatically actuated artificial muscles and one linear actuator to obtain an overall 15 DOF device. The design is a combination of rigid and soft elements. The artificial muscles are connected to tendon cables that in turn flex the specified digits upon actuation. A linear spring provides the counter extension forces for each digit. The control of the device utilizes both position and force control and regulates the pressure of the muscles through a solenoid valve. The authors created a novel polypyrrole sensor that consists of a conductive polymer in which conductivity is measured through deformation to determine the position of the finger. This is an innovative step in hand exoskeleton technology, and more research is needed on these types of sensors.

\subsection{Tang et al.}

This paper presented a hand exoskeleton that is able to assist rehabilitation exercises. A four-bar mechanical linkage system was validated by kinematic modeling, static analysis, and finite element analysis. The device was optimized for better kinematic performance as well as being able to adjust to various users. A differential rotational actuator based on shape memory alloy was proposed [39].

Shape memory alloy relies on current for heating the alloy to allow expansion. SMA has drawbacks in which heat is generated in the regions of $100{ }^{\circ} \mathrm{C}+$ as well as requires a large amount of power input in the region of $2 \mathrm{~A}$. The system developed has a cycle of $12 \mathrm{~s}-3 \mathrm{~s}$ for heating, and 9 for cooling - and it produces an output force on the spring of $0-27 \mathrm{~N}$. A longer time is required to get an appropriate operating force. 


\subsection{Cempini et al.}

This paper presents a new hand exoskeleton design, which is lightweight, portable, safe, and can fit various hand sizes and execute different exercises [33]. The design focuses on the mechanism of flexion and extension of the index finger and thumb with a passive abduction/adduction movement. The MCP, PIP, and DIP joints of the finger are essentially modeled as revolute joints. The design features a matched axis topology.

This underactuated system consists of a Bowden cable setup, with a remote actuation due to the lower inertia, but also the reliability and precision bandwidth. It consists of two actuators: one that regulates the MCP joint net torque and the other that actuated the PIP and DIP joints. The weight of the hand exoskeleton is around $500 \mathrm{~g}$ and the actuation unit is around $1 \mathrm{~kg}$.

The authors have implemented a self-aligning prismatic joint mechanism for the MCP joint. However, they did not consider alignment for the PIP and DIP joints. Their solution was to add a neoprene soft cover between the links to minimize small errors.

\subsection{Zhang et al.}

Zhang et al. [59] present a hand exoskeleton designed for the purpose to rehabilitate hands due to injuries. A unique design is presented that offers a circuitous joint to each of the finger joints. The device can easily adjust to various hand sizes and can cover a wide range of the hand and finger workspace. The rigid mechanism of the hand exoskeleton utilizes a rack and pinion slide for the adjustments and is actuated through a Bowden cable setup driven by DC motors. The finger joints are equipped with position sensors as well as force sensors for feedback to the therapist and control system.

\subsection{Lambercy et al.}

Lambercy et al. [40] created a thumb exoskeleton for the main purpose to rehabilitate lost functions of the thumb and add thumb opposition to the therapy process. The exoskeleton allows flexion/extension and abduction/adduction to work in combination to achieve the circular cone-shaped opposition by using a single active linear actuator and passive joints to transmit the motion through a four-bar linkage (redundant) mechanism. The design features the adjustment to various finger sizes and can be easily donned and doffed. The design features three adjustment points to align the exoskeleton to the hand and be as comfortable as possible. The linear actuator can move in a linear direction, allowing the device to align the MCP joint correctly. The four-bar linkage mechanism has two passive prismatic joints to further align the exoskeleton phalanges to the thumb phalanges. The interaction point of the exoskeleton and the finger phalanges are shaped to have the thumb seated firmly inside the structure with Velcro straps securing the device. The base plate holding the actuator is also connected to the dorsal side of the hand through Velcro straps connected to the wrist and palm. The exoskeleton was constructed from 3D printed manufacturing.

\subsection{Iqbal et al.}

Iqbal et al. design a novel hand exoskeleton to assist finger flexion and extension during rehabilitation exercises [43]. This device is an underactuated, direct-driven device with a base-to-distal serial linkage topology structured design. In this design, the actuation unit applies a perpendicular force to the proximal phalange instead of the distal phalange. The serial mechanism consists of a revolute-revolute-revolute (RRR) joint structure. The authors implemented a minimum jerk control strategy to achieve a smooth actuation.

\subsection{Open Fingerpad eXoskeleton (OFX)}

Heo et al. created an exoskeleton with an open fingerpad for object manipulation and power assistance [60]. The device is actuated through pneumatic cylinders, which apply the assistive force measured by the fingertip pinch grip. A load cell is applied to the tip of the distal phalange with a unique structure to have the fingerpad of the user open. The 
device features the actuation of the index finger and thumb. The authors used SEMG as a sensor to measure muscle fatigue upon operation.

\subsection{Polygerinos et al.}

Polygerinos et al. present a soft robotic glove that can be used for assistance or at-home rehabilitation [50]. The actuator or bending mechanism of this exoskeleton is made from molded elastomeric chambers with fiber reinforcements to induce bending at certain points and certain pressures of the chambers. This soft glove uses a hydraulic fluid instead of pneumatics as a new approach to actuate and bend the fingers. Fluid pressure sensors are used to determine the pressure and in turn control the motion of the hand. The actuation unit is situated in a belt carried on the waist of the patient to minimize the weight on the hand. The soft hand device weighs around $285 \mathrm{~g}$ and the waist pack weighs around $3.3 \mathrm{~kg}$. This structure is known as the jointless structure topology.

\subsection{ExoGlove}

Yap et al. presented a soft exoskeleton that is made for assistance or rehabilitation purposes but contains a unique design feature with variable stiffness [51]. The glove is pneumatically actuated through flexible jointless actuators that bend at certain areas (due to the variance in stiffness) when pressurized. Each actuator is custom made for a certain finger length as well as for various bending profiles or rehabilitation training tasks. As in the previous design, the actuation unit containing the pump, valves, etc. is situated in a belt on the waist of the patient. Flex sensors are attached to the bottom of the glove to measure the bending profile of each finger.

\subsection{Agarwal et al.}

Agarwal et al. created an index finger exoskeleton for rehabilitation [61]. The device has a mechanical redundant structure but features a Bowden cable series elastic actuator transmission to increase the accuracy of bidirectional force and torque measurements and control. The whole design has high backdrivability and low inertia. The mechanical design can easily fit various users and can achieve a good finger ROM.

\subsection{Exo-Glove}

In et al. introduce a soft tendon-driven exoskeleton with a unique cable routing system [47]. The actuator is also unique in design to operate without any pretension in the cables improving safety, comfort, and efficiency.

Experiments were executed to validate the design and proved to restore grasping functions of disabled individuals.

A fabric glove with Teflon tubes is used to route the cables. There are two tendons for each finger and the thumb. The glove is adjustable to obtain the right ROM by adjusting the fabric straps on the glove. The tendons are routed through Teflon tubes stitched between the fabric on the left and right side of the phalanges. The system is underactuated, meaning that fewer actuators are used for the number of actuated fingers. One tendon is routed through the index and middle fingers to flex them together for grasping objects.

Admittance control is used to make the device a virtual spring. Wrist motion is used to actuate the glove, due to the reliability and the familiar feeling to disabled individuals according to the tenodesis effect.

The device was able to assist the disabled individuals as well as improve their grasping functions.

\subsection{Cui et al.}

Cui et al. developed this device intending to design and develop a novel threedimensional (3D) printable non-assembly five-fingered robotic hand exoskeleton for rehabilitation [37]. 
This design introduced a novel hand orthosis in which each finger is driven by one actuator and has three output links. The 2nd to 5th digits are designed to have three links and consist of an eight-bar 10-joint linkage system formulated using Grubler's formula. The thumb has two output links and consists of a single DOF with a six-bar seven-joint mechanism.

Each finger has three linkages corresponding to the number of phalanges of the finger. The orthosis is designed in such a way to minimize the size and sensory feedback interference of the mechanism. Each finger is driven by one linear actuator to ensure it has low inertia.

Each orthosis is designed to a specific human hand size; therefore, it is not adjustable to various hand sizes. Although it is designed to be $3 \mathrm{D}$ printed, which minimizes the production cost.

This study introduced a new planar linkage mechanism capable of actuating the phalanges of a finger with one linear actuator. The device utilized an eight-bar, seven-joint singe DOF unique structure but suffers from a few flaws that will be addressed in the future such as the lack of implementation of force sensors for feedback as well as the device not being strong enough for rehabilitation purposes.

\subsection{Haghshenas-Jaryani et al.}

This design presents a pneumatic hybrid soft/rigid glove capable of executing continuous passive motion (CPM) therapy. The actuator has flexible bellows-type hollow structures linked with semi-rigid connecting sections to flex and extend the finger according to its ROM and finger trajectory. The glove is custom-made for a patient. A pneumatic feedback control system is utilized to control the bending motion of the fingers.

\subsection{Sandoval-Gonzalez et al.}

Sandoval-Gonzalez et al. present the design and development of a hand exoskeleton with the focus on hand motor rehabilitation for patients with neuromusculoskeletal motor disabilities [63]. The device is designed to be lightweight, compact, have adequate torque, and can adapt to different finger sizes. It can also accommodate various palm/hand sizes. The system is designed to have independent active flexion/extension motions and passive abduction/adduction movements.

The main mechanical objective is to achieve the independent movement of the phalanges. The device has six DOF for each finger. The 1st DOF is prismatic displacement, the 2 nd is passive abduction/adduction motion, the 3rd and 4th are for the flex/extend of proximal and distal phalanges, the 5th is for telescopic movement of proximal and distal phalanges, the 6th is a proximal phalange cylindrical axis mechanism for linear movement.

The driving mechanism is a DC motor with a worm gear driving a spur gear that is connected to the phalanges to flex and extend them. It is designed to rotate at a rate of $97.2^{\circ} / \mathrm{s}(16.66 \mathrm{rpm})$ and has a torque of $5 \mathrm{~kg}-\mathrm{cm}$. The device also offers position control for the therapist to adjust the forces to the patient's comfort.

\subsection{Popov et al.}

Popov et al. present a new portable hand exoskeleton glove for the assistance of the activities of daily living [48]. A hand exoskeleton was developed, which is lightweight, adjustable, soft, and does not constrain the wrist motion. The thumb, index, middle, and ring fingers are actively controlled with bidirectional actuators for flexion and extension.

One major aim is to have a high power to weight ratio and portable device.

The glove is made from stacking layers on top of each other. The 1st layer is a soft glove to ensure wearing comfort. The 2 nd layer consists of a stiffer material on to which the actuators and cable routing paths can be mounted. The 3rd layer is the actuator and cables, and the 4 th layer is a cover to hide the mechanical system. A geared DC motor along with elastic, low friction cables are used for the actuation to flex and extend the fingers. 


\subsection{HES}

Conti et al. created a portable, low-cost functional hand exoskeleton (HES) for the purpose to assist individuals with hand-opening impairments. The device is a rigid mechanical structure that attaches to only one phalange (the distal with supports on the middle), has only one DOF, and which is cable-driven for flexion and extension. The exoskeleton is designed in such a way to fit various hand sizes and can accomplish the opening and closing of the hand.

\subsection{Mano}

Randazzo et al. presents a novel hand exoskeleton design to assist and restore the motor functions of impaired individuals and improve their quality of life [66]. The device is wearable, portable, and does not obstruct the hand as much. A BCI with EEG is implemented to control the hand through pattern detection.

The fingers are actuated using Bowden cables, a linear actuator and each finger have one active DOF, flexion, and extension. Abduction and adduction can be passively controlled by the user. The device is made to be low cost; therefore, off-shelf parts are used as well as 3D printing and laser cutters. The actuators are situated in a confined box mounted on the chest, with the Bowden cables connecting the fingers. The device is powered by a Lithium Polymer ( $\mathrm{LiPo}$ ) battery and can run for up to $3 \mathrm{~h}$ continuously.

\subsection{ReHand}

Wang et al. present the design of a portable hand exoskeleton for rehabilitation. The design has many focused requirements such as lightweight, portable, cheap, long endurance, and adjustable to various users. The hand exoskeleton can actuate the fingers and thumb independently. The structure consists of an underactuated sliding mechanism to reduce weight and keep it simple. The four fingers are actuated at the same time by one actuator. This device is also controlled through sEMG as well as a voice control system for evaluation.

\subsection{Akgun et al.}

Akgun et al. present a new simple hand exoskeleton design and a new control scheme for increasing the safety of the device [72]. An adaptive compliance control is implemented where the dynamic parameters are estimated and actuated accordingly. The control scheme claims to be better than traditional position control.

The device consists of a two, four-bar mechanical linkage system driven by a linear actuator. The device actively controls the PIP and MCP joints with one actuator, making the system underactuated.

Adaptive impedance control is used. A two DOF virtual system is used to determine the dynamic parameters and can feed the information back to the actual controller; this is done to control any unwanted forces acted out on the device by the patient's injury. An online parameter estimator is used to obtain the dynamic parameters.

\section{Conclusions}

The hand is one of the most complex anatomical structures in the human body due to its high DOF and great ROM in a small and compact space. Things become even more difficult for engineers to replicate the entire motions of the hand. Therefore, understanding the biomechanics of the hand is an important factor for developing systems that can mimic the motions and possibly benefit disabled and healthy individuals. Luckily, designers have been working on such devices, and the technology has rapidly advanced since then. These devices were mainly focused on rehabilitating and assisting disabled individuals and improving their life quality. Technology advances daily, and devices providing haptic feedback to virtual and teleoperation applications are also an emerging field with great advances. This paper also includes haptic as well as power amplification devices with the focus placed on rehabilitation and assistive technologies. 
Several research studies over the past decade were introduced in this paper. A comprehensive summary of all the identified design requirements for the various types of hand exoskeletons (rehabilitation, assistance, augmentation, and haptic) as well as the fundamental technologies and challenges surrounding this area of research is presented. There already exist a few hand exoskeletons for commercial use, and it is a good indication that the developed technology can be used for its intended purpose, especially for rehabilitation. However, challenges still arise for assistive hand exoskeleton devices. Mostly, all devices reviewed were either still in development with promising practical outcomes, only tested and used in a laboratory setting, or developed for strictly indoor clinical environments. The outdoor environment is still a challenge that engineers face due to the number of disturbances the device can experience. This is especially the case with the emerging intelligent user intention detection control systems that are developed, such as EEG or EMG measuring devices.

The basic building blocks and technologies used in designs, over the past decade, were comprehensively discussed and presented systematically to easily understand the various fundamental concepts and advancements made in this area. The actuation, power transmission, sensing, and control were identified and discussed, which has the intention to focus the attention on the existing technology and the future trend of this paper. Lastly, short summaries of each article that had a significant contribution to the exoskeleton technologies have briefly been explained. Upon observation, devices recently developed had both rigid and soft elements, which lead to the conclusion that future designs may consist of rigid and soft hybrid materials and have an intention detection control for assistance to help humans (disabled or healthy) in everyday tasks.

Author Contributions: Conceptualization, T.d.P. and K.D.; methodology, K.D. and T.d.P.; formal analysis, T.d.P.; investigation, T.d.P.; resources, T.d.P.; writing—original draft preparation, T.d.P.; writing-review and editing, C.O. and K.D.; visualization, T.d.P.; supervision, K.D. and C.O.; project administration, T.d.P.; funding acquisition, K.D. All authors have read and agreed to the published version of the manuscript.

Funding: This research was funded by the National Research Foundation (NRF) of South Africa (Grant Number: 90604). Opinions, findings, and conclusions or recommendations expressed in any publication generated by the NRF supported research are those of the author(s) alone, and the NRF accepts no liability whatsoever in this regard.

Institutional Review Board Statement: Ethical review and approval were waived for this study, due to the pure use of literature to obtain the results.

Informed Consent Statement: Not applicable.

Data Availability Statement: Data sharing not applicable. No new data were created or analyzed in this study. Data sharing is not applicable to this review paper.

Acknowledgments: Our thanks go to the French South African Institute of Technology (F'SATI) for their ongoing support and cooperation.

Conflicts of Interest: The authors declare no conflict of interest. The funders had no role in the design of the study; in the collection, analyses, or interpretation of data; in the writing of the manuscript, or in the decision to publish the results.

\section{References}

1. Hardiman, G.E.I. Exoskeleton. Mosher, R. (American). Cyberneticzoo. 2010, pp. 1965-1971. Available online: http:// cyberneticzoo. com/man-amplifiers/1966-69-g-e-hardiman-i-ralph-mosher-american/ (accessed on 17 September 2020).

2. Burdea, G.C. Portable Dextrous Force Feedback Master for Robot Telemanipulation USA. 1989. Available online: https:/ / patents. google.com/patent/US5004391A/en (accessed on 18 September 2020).

3. Meng, Q.; Xiang, S.; Yu, H. Soft Robotic Hand Exoskeleton Systems: Review and Challenges Surrounding the Technology. In Proceedings of the 2017 2nd International Conference on Electrical, Automation and Mechanical Engineering (EAME 2017), Shanghai, China, 23-24 April 2017; Atlantis Press: Paris, France, 2017. [CrossRef]

4. Ferris, D.P. The exoskeletons are here. J. Neuroeng. Rehabil. 2009, 6, 17. [CrossRef] 
5. WHO. World Report on Disability. 2011. Available online: https://www.who.int/publications/i/item/9789241564182 (accessed on 23 September 2020).

6. Reitan, I.; Dahlin, L.B.; Rosberg, H.-E. Patient-reported quality of life and hand disability in elderly patients after a traumatic hand injury-A retrospective study. Health Qual. Life Outcomes 2019, 17, 1-10. [CrossRef] [PubMed]

7. Brown, J.M. Spinal Cord Injury. Available online: https://www.paralysiscenter.org/spinal-cord-injury?gclid=CjwKCAiA8JfBRB-EiwAWDtEGnsd97nHvJgpTSYOZm3rrt3iAicf9wjXlaHXbAdVjqFdPQE7oIwa7hoCA9cQAvD_BwE (accessed on 4 August 2020).

8. Langhorne, P.; Bernhardt, J.; Kwakkel, G. Stroke rehabilitation. Lancet 2011, 377, 1693-1702. [CrossRef]

9. Krichevets, A.N.; Sirotkina, E.B.; Yevsevicheva, I.V.; Zeldin, L.M. Computer games as a means of movement rehabilitation. Disabil. Rehabil. 1995, 17, 100-105. [CrossRef] [PubMed]

10. Lum, P.S.; Burgar, C.G.; Shor, P.C.; Majmundar, M.; Van Der Loos, M. Robot-assisted movement training compared with conventional therapy techniques for the rehabilitation of upper-limb motor function after stroke. Arch. Phys. Med. Rehabil. 2002, 83, 952-959. [CrossRef] [PubMed]

11. Staubli, P.; Nef, T.; Klamroth-Marganska, V.; Riener, R. Effects of intensive arm training with the rehabilitation robot ARMin II in chronic stroke patients: Four single-cases. J. Neuroeng. Rehabil. 2009, 6, 46. [CrossRef]

12. Schabowsky, C.N.; Godfrey, S.B.; Holley, R.J.; Lum, P.S. Development and pilot testing of HEXORR: Hand EXOskeleton Rehabilitation Robot. J. Neuroeng. Rehabil. 2010, 7, 36. [CrossRef]

13. Kim, S.; Nussbaum, M.A.; Esfahani, M.I.M.; Alemi, M.M.; Alabdulkarim, S.; Rashedi, E. Assessing the influence of a passive, upper extremity exoskeletal vest for tasks requiring arm elevation: Part I-Expected effects on discomfort, shoulder muscle activity, and work task performance. Appl. Erg. 2018, 70, 315-322. [CrossRef]

14. Kim, S.; Nussbaum, M.A.; Esfahani, M.I.M.; Alemi, M.M.; Jia, B.; Rashedi, E. Assessing the influence of a passive, upper extremity exoskeletal vest for tasks requiring arm elevation: Part II-Unexpected effects on shoulder motion, balance, and spine loading. Appl. Erg. 2018, 70, 323-330. [CrossRef]

15. Troncossi, M.; Mozaffari-Foumashi, M.; Parenti-Castelli, V. An Original Classification of Rehabilitation Hand Exoskeletons. J. Robot. Mech. Eng. Res. 2016, 1, 17-29. [CrossRef]

16. Ferguson, P.W.; Shen, Y.; Rosen, J. Hand Exoskeleton Systems-Overview in Wearable Robotics, 1st ed.; Rosen, J., Ferguson, P.W., Eds.; Elsevier: Amsterdam/Holland, The Netherlands, 2020; pp. 149-175.

17. Heo, P.; Gu, G.M.; Lee, S.J.; Rhee, K.; Kim, J. Current hand exoskeleton technologies for rehabilitation and assistive engineering. Int. J. Precis. Eng. Manuf. 2012, 13, 807-824. [CrossRef]

18. Sarac, M.; Solazzi, M.; Frisoli, A. Design Requirements of Generic Hand Exoskeletons and Survey of Hand Exoskeletons for Rehabilitation, Assistive, or Haptic Use. IEEE Trans. Haptics 2019, 12, 400-413. [CrossRef] [PubMed]

19. Birouas, F.; Avram, F.; Nilgesz, A.; Mihalca, V.O. A review regarding hand exoskeleton technologies for rehabilitation. Recent Innov. Mechatron. 2018, 5, 1-5. [CrossRef]

20. Shahid, T.; Gouwanda, D.; Nurzaman, S.G.; Gopalai, A.A. Moving toward Soft Robotics: A Decade Review of the Design of Hand Exoskeletons. Biomimetics 2018, 3, 17. [CrossRef]

21. Chu, C.-Y.; Patterson, R.M. Soft robotic devices for hand rehabilitation and assistance: A narrative review. J. Neuroeng. Rehabil. 2018, 15, 1-14. [CrossRef]

22. Waugh, A.; Grant, A.; Ross, W. Anatomy and Physiology in Health and Illness, 11th ed.; Elsevier: Amsterdam, The Netherlands; Churchill Livingstone: London, UK, 2012.

23. BabySparks. Hand-Eye Coordination: How the Eyes, Brain \& Hands Work Together. 2019. Available online: https://babysparks. com/2019/05/14/hand-eye-coordination-how-the-eyes-brain-and-hands-work-together/ (accessed on 2 December 2020).

24. Taylor, C.L.; Schwarz, R.J. The anatomy and mechanics of the human hand. Artif. Limbs 1955, 2, 22-35.

25. Hirt, B.; Seyhan, H.; Wagner, M. Hand and Wrist Anatomy and Biomechanics: A Comprehensive Guide, Stuttgart, Germany: Thieme. 2017. Available online: http://eds.a.ebscohost.com/eds/detail/detail?vid=1\&sid=3c66ae5b-ea04-4c5b-bf60-cab0a140 b317\%40sessionmgr4008\&bdata=JkF1dGhUeXB1PWlwLHVybCxjb29raWUsdWlkJnNpdGU9ZWRzLWxpdmU\%3d\#AN=1402 $887 \& \mathrm{db}=\mathrm{e} 000 \mathrm{xww}$ (accessed on 10 June 2020).

26. Nanayakkara, V.K.; Cotugno, G.; Vitzilaios, N.; Venetsanos, D.; Nanayakkara, T.; Sahinkaya, M.N. The Role of Morphology of the Thumb in Anthropomorphic Grasping: A Review. Front. Mech. Eng. 2017, 3, 06-30. [CrossRef]

27. Wang, L.; Meydan, T.; Williams, P.I. A Two-Axis Goniometric Sensor for Tracking Finger Motion. Sensors 2017, 17, 770. [CrossRef]

28. Napier, J.R. The prehensile movements of the human hand. Bone Jt. J. 1956, 38, 902-913. [CrossRef]

29. Feix, T.; Romero, J.; Schmiedmayer, H.-B.; Dollar, A.M.; Kragic, D. The GRASP Taxonomy of Human Grasp Types. IEEE Trans. Hum. -Mach. Syst. 2016, 46, 66-77. [CrossRef]

30. Patkin, MA CheckList for Handle Design. 2001. Available online: https://mpatkin.org/ergonomics/handle_checklist.htm (accessed on 3 October 2020).

31. Cempini, M.; Cortese, M.; Vitiello, N. A Powered finger-thumb wearable hand exoskeleton with self-aligning joint axes. IEEE/ASME Trans. Mechatron. 2014, 20, 705-716.

32. Chiri, A.; Vitiello, N.; Giovacchini, F.; Roccella, S.; Vecchi, F.; Carrozza, M.C. Mechatronic Design and Characterization of the Index Finger Module of a Hand Exoskeleton for Post-Stroke Rehabilitation. IEEE/ASME Trans. Mechatron. 2011, 17, 884-894. [CrossRef] 
33. Cempini, M.; De Rossi, S.M.M.; Lenzi, T.; Cortese, M.; Giovacchini, F.; Vitiello, N.; Carrozza, M.C. Kinematics and design of a portable and wearable exoskeleton for hand rehabilitation. In Proceedings of the 2013 IEEE 13th International Conference on Rehabilitation Robotics (ICORR), Seattle, WA, USA, 24-26 June 2013; pp. 1-6.

34. Battezzato, A. Kinetostatic analysis and design optimization of an n-finger underactuated hand exoskeleton. Mech. Mach. Theory 2015, 88, 86-104. [CrossRef]

35. Tong, K.; Ho, S.; Pang, P.; Hu, X.; Tam, W.; Fung, K.; Wei, X.; Chen, P.; Chen, M. An intention driven hand functions task training robotic system. In Proceedings of the 2010 Annual International Conference of the IEEE Engineering in Medicine and Biology, Buenos Aires, Argentina, 31 August-4 September 2010; pp. 3406-3409.

36. Ockenfeld, C.; Tong, R.K.Y.; Susanto, E.A.; Ho, S.-K.; Hu, X.-L. Fine finger motor skill training with exoskeleton robotic hand in chronic stroke: Stroke rehabilitation. In Proceedings of the 2013 IEEE 13th International Conference on Rehabilitation Robotics (ICORR), Seattle, WA, USA, 24-26 June 2013; pp. 1-4.

37. Cui, L.; Phan, A.; Allison, G. Design and fabrication of a three dimensional printable non-assembly articulated hand exoskeleton for rehabilitation. In Proceedings of the 2015 37th Annual International Conference of the IEEE Engineering in Medicine and Biology Society (EMBC), Milan, Italy, 25-29 August 2015; pp. 4627-4630.

38. Wang, D.; Meng, Q.; Meng, Q.; Li, X.; Yu, H. Design and Development of a Portable Exoskeleton for Hand Rehabilitation. IEEE Trans. Neural Syst. Rehabil. Eng. 2018, 26, 2376-2386. [CrossRef] [PubMed]

39. Tang, T.; Zhang, D.; Xie, T.; Zhu, X. An exoskeleton system for hand rehabilitation driven by shape memory alloy. In Proceedings of the 2013 IEEE International Conference on Robotics and Biomimetics (ROBIO), Shenzhen, China, 12-14 December 2013; pp. 756-761.

40. Lambercy, O.; Schröder, D.; Zwicker, S.; Gassert, R. Design of a thumb exoskeleton for hand rehabilitation. Presented at the International Convention on Rehabilitation Engineering and Assistive Technology (i-CREATe), Zurich, Switzerland, 13 September 2013; Available online: https://www.researchgate.net/publication/259910946_Design_of_a_thumb_exoskeleton_for_hand_ rehabilitation (accessed on 4 June 2020).

41. Conti, R.; Meli, E.; Ridolfi, A. A novel kinematic architecture for portable hand exoskeletons. Mechatronics 2016, 35, 192-207. [CrossRef]

42. Jo, I.; Bae, J. Design and control of a wearable and force-controllable hand exoskeleton system. Mechatronics 2017, 41, 90-101. [CrossRef]

43. Iqbal, J.; Khan, H.; Tsagarakis, N.G.; Caldwell, D.G. A novel exoskeleton robotic system for hand rehabilitationConceptualization to prototyping. Biocybern. Biomed. Eng. 2014, 34, 79-89.

44. Sarakoglou, I.; Brygo, A.; Mazzanti, D.; Hernandez, N.G.; Caldwell, D.G.; Tsagarakis, N.G. HEXOTRAC: A highly Un-derActuated Hand Exoskeleton for Finger Tracking and Force Feedback. Presented at the IEEE/RSJ International Conference on Intelligent Robots and Systems (IROS), Daejeon, Korea, 9-14 October 2016; Available online: https://ieeexplore.ieee.org/ document/7759176 (accessed on 5 June 2020).

45. Tjahyono, A.P.; Aw, K.C.; Devaraj, H.; Surendra, W.; Haemmerle, E. A five-fingered hand exoskeleton driven by pneumatic artificial muscles with novel polypyrrole sensors. Ind. Robot Int. J. 2013, 40, 251-260. [CrossRef]

46. Yang, J.; Xie, H.; Shi, J. A novel motion-coupling design for a jointless tendon-driven finger exoskeleton for rehabilitation. Mech. Mach. Theory 2016, 99, 83-102. [CrossRef]

47. In, H.; Kang, B.B.; Sin, M.; Cho, K.-J. Exo-Glove: A Wearable Robot for the Hand with a Soft Tendon Routing System. IEEE Robot. Autom. Mag. 2015, 22, 97-105. [CrossRef]

48. Popov, D.; Gaponov, I.; Ryu, J.-H. Portable Exoskeleton Glove with Soft Structure for Hand Assistance in Activities of Daily Living. IEEE/ASME Trans. Mechatron. 2016, 22, 865-875. [CrossRef]

49. Kazeminasab, S.; Hadi, A.; Alipour, K.; Elahinia, M. Force and motion control of a tendon-driven hand exoskeleton actuated by shape memory alloys. Ind. Robot. Int. J. 2018, 45, 623-633. [CrossRef]

50. Polygerinos, P.; Wang, Z.; Galloway, K.C.; Wood, R.J.; Walsh, C.J. Soft robotic glove for combined assistance and at-home rehabilitation. Robot. Auton. Syst. 2015, 73, 135-143. [CrossRef]

51. Yap, H.K.; Lim, J.H.; Nasrallah, F.; Goh, J.C.H.; Yeow, R.C.H. A soft exoskeleton for hand assistive and rehabilitation application using pneumatic actuators with variable stiffness. Presented at the International Conference on Robotics and Automation, Seattle, WA, USA, 26-30 May 2015; Available online: https:/ / ieeexplore.ieee.org/abstract/document/7139889 (accessed on 2 June 2020).

52. Yap, H.K.; Ang, B.W.K.; Lim, J.H.; Goh, J.C.H.; Yeow, C.-H. A fabric-regulated soft robotic glove with user intent detection using EMG and RFID for hand assistive application. In Proceedings of the 2016 IEEE International Conference on Robotics and Automation (ICRA), Stockholm, Sweden, 16-21 May 2016; pp. 3537-3542.

53. Haghshenas-Jaryani, M.; Carrigan, W.; Nothnagle, C.; Wijesundara, M.B.J. Sensorized soft robotic glove for continuous passive motion therapy. In Proceedings of the 2016 6th IEEE International Conference on Biomedical Robotics and Biomechatronics (BioRob), Singapore, 26-29 June 2016; pp. 815-820.

54. Al-Fahaam, H.; Davis, S.; Nefti-Meziani, S.; Theodoridis, T. Novel soft bending actuator-based power augmentation hand exoskeleton controlled by human intention. Intell. Serv. Robot. 2018, 11, 247-268. [CrossRef]

55. Boser, Q.A.; Dawson, M.R.; Schofield, J.S.; Dziwenko, G.Y.; Hebert, J.S. Defining the design requirements for an assistive powered hand exoskeleton: A pilot explorative interview study and case series. Prosthet. Orthot. Int. 2020. [CrossRef] [PubMed] 
56. Iqbal, J.; Tsagarakis, N.G.; Caldwell, D.G. A multi-DOF robotic exoskeleton interface for hand motion assistance. In Proceedings of the 2011 Annual International Conference of the IEEE Engineering in Medicine and Biology Society, Boston, MA, USA, 30 August-3 September 2011; Volume 2011, pp. 1575-1578.

57. Li, J.; Zheng, R.; Zhang, Y.; Yao, J. iHandRehab: An interactive hand exoskeleton for active and passive rehabilitation. In Proceedings of the 2011 IEEE International Conference on Rehabilitation Robotics, Zurich, Switzerland, 29 June-1 July 2011 ; pp. 1-6.

58. Rahman, A.; Al-Jumaily, A. Design and Development of a Hand Exoskeleton for Rehabilitation Following Stroke. Procedia Eng. 2012, 41, 1028-1034. [CrossRef]

59. Zhang, F.; Hua, L.; Fu, Y.; Chen, H.; Wang, S. Design and development of a hand exoskeleton for rehabilitation of hand injuries. Mech. Mach. Theory 2014, 73, 103-116. [CrossRef]

60. Heo, P.K.J. Power-Assistive Finger Exoskeleton with a Palmar Opening at the Fingerpad. IEEE Trans. Biomed. Eng. 2014, 61, 2688-2697. [CrossRef]

61. Agarwal, P.; Fox, J.; Yun, Y.; O’Malley, M.K.; Deshpande, A.D. An index finger exoskeleton with series elastic actuation for rehabilitation: Design, control and performance characterization. Int. J. Robot. Res. 2015, 34, 1-26. [CrossRef]

62. Bataller, A.; Cabrera, J.A.; Clavijo, M.; Castillo, J.J. Evolutionary synthesis of mechanisms applied to the design of an exoskeleton for finger rehabilitation. Mech. Mach. Theory 2016, 105, 31-43. [CrossRef]

63. Sandoval-Gonzalez, O.; Jacinto-Villegas, J.M.; Herrera-Aguilar, I.; Portillo-Rodiguez, O.; Tripicchio, P.; Hernandez-Ramos, M.; Flores-Cuautle, A.; Avizzano, C. Design and development of a hand exoskeleton robot for active and passive rehabilitation. Int. J. Adv. Robot. Syst. 2016, 13, 66. [CrossRef]

64. Ben Abdallah, I.; Bouteraa, Y.; Rekik, C. Design and development of 3d printed myoelectric robotic exoskeleton for hand rehabilitation. Int. J. Smart Sens. Intell. Syst. 2017, 10, 341-366. [CrossRef]

65. Bianchi, M.; Cempini, M.; Conti, R.; Meli, E.; Ridolfi, A.; Vitiello, N.; Allotta, B. Desing of a Series Elastic Transmission for hand exoskeletons. Mechatronics 2018, 51, 8-18. [CrossRef]

66. Randazzo, L.; Iturrate, I.; Perdikis, S.; Millan, J.D.R. Mano: A wearable hand exoskeleton for activities of daily living and neurorehabilitation. IEEE Robot. Autom. Lett. 2018, 3, 500-507. [CrossRef]

67. Jo, I.; Park, Y.; Lee, J.; Bae, J. A portable and spring-guided hand exoskeleton for exercising flexion/extension of the fingers. Mech. Mach. Theory 2019, 135, 176-191. [CrossRef]

68. Li, M.; He, B.; Liang, Z.; Zhao, C.G.; Chen, J.; Zhuo, Y.; Xu, G.; Xie, J.; Althoefer, K. An attention-controlled hand exoskeleton for the rehabilitation of finger extension and flexion using a rigid-soft combined mechanism . Front. Neurorobot 2019, 13, 1-13.

69. Marconi, D.; Baldoni, A.; McKinney, Z.; Cempini, M.; Crea, S.; Vitiello, N. A novel hand exoskeleton with series elastic actuation for modulated torque transfer. Mechatronics 2019, 61, 69-82. [CrossRef]

70. Bützer, T.; Lambercy, O.; Arata, J.; Gassert, R. Fully wearable actuated soft exoskeleton for grasping assistance in everyday activities. Soft Robot. 2020, 1-16. [CrossRef]

71. Wang, S.; Li, J.; Zheng, R. Active and passive control algorithm for an exoskeleton with bowden cable transmission for hand rehabilitation. In Proceedings of the 2010 IEEE International Conference on Robotics and Biomimetics, Tianjin, China, 14-18 December 2010; pp. 75-79.

72. Akgun, G.; Cetin, A.E.; Kaplanoglu, E. Exoskeleton design and adaptive compliance control for hand rehabilitation. Trans. Inst. Meas. Control. 2019, 42, 493-502. [CrossRef]

73. Li, J.; Wang, S.; Wang, J.; Zheng, R.; Zhang, Y.; Chen, Z. Development of a Hand Exoskeleton System for Index Finger Rehabilitation. Chin. J. Mech. Eng. 2012, 25, 223-232. [CrossRef]

74. Zhou, M.A.; Pinhas, B.T. RML Glove-An exoskeleton glove mechanism with haptics feedback. IEEE/ASME Trans. Mechatron. 2014, 20, 641-652.

75. Mohamaddan, S.; Komeda, T. Wire-driven mechanism for finger rehabilitation device. In Proceedings of the 2010 IEEE International Conference on Mechatronics and Automation, Xi'an, China, 4-7 August 2010; pp. 1015-1018.

76. In, H.; Cho, K.-J.; Kim, K.; Lee, B. Jointless structure and under-actuation mechanism for compact hand exoskeleton. In Proceedings of the 2011 IEEE International Conference on Rehabilitation Robotics, Zurich, Switzerland, 29 June-1 July 2011 ; pp. 1-6.

77. Nilsson, M.; Ingvast, J.; Wikander, J.; Von Holst, H. The Soft Extra Muscle system for improving the grasping capability in neurological rehabilitation. In Proceedings of the 2012 IEEE-EMBS Conference on Biomedical Engineering and Sciences, Langkawi, Malaysia, 17-19 December 2012; pp. 412-417.

78. Serbest, K.; Eldogan, O. Design, development and evaluation of a new hand exoskeleton for stroke rehabilitation at home. J. Polytech. 2020, 24, 305-314.

79. Yap, H.K.; Lim, J.H.; Nasrallah, F.; Yeow, C.-H. Design and Preliminary Feasibility Study of a Soft Robotic Glove for Hand Function Assistance in Stroke Survivors. Front. Neurosci. 2017, 11, 547. [CrossRef]

80. Villoslada, A.; Rivera, C.; Escudero, N.; Martín, F.; Blanco, D.; Moreno, L. Hand exo-muscular system for assisting as-tronauts during extravehicular activities. Soft Robot. 2018, 6, 11-20.

81. Shields, B.L.; Main, J.A.; Peterson, S.W.; Strauss, A.M. An anthropomorphic hand exoskeleton to prevent astronaut hand fatigue during extravehicular activities. IEEE Trans. Syst. Man Cybern. Part A Syst. Hum. 1997, 27, 668-673. [CrossRef] 
82. Ates, S.; Haarman, C.J.W.; Stienen, A.H.A. SCRIPT passive orthosis: Design of interactive hand and wrist exoskeleton for rehabilitation at home after stroke. Auton. Robot. 2016, 41, 711-723. [CrossRef]

83. Saebo. SaeboGlove. 2001. Available online: https://www.saebo.com/shop/saeboglove/ (accessed on 14 August 2020).

84. Brokaw, E.B.; Black, I.; Holley, R.J.; Lum, P.S. Hand Spring Operated Movement Enhancer (HandSOME): A Portable, Passive Hand Exoskeleton for Stroke Rehabilitation. IEEE Trans. Neural Syst. Rehabil. Eng. 2011, 19, 391-399. [CrossRef]

85. Iqbal, J.; Tsagarakis, N.G.; Caldwell, D.G. A human hand compatible optimised exoskeleton system. In Proceedings of the 2010 IEEE International Conference on Robotics and Biomimetics, Tianjin, China, 14-18 December 2010; pp. 685-690.

86. Kim, S.; Lee, J.; Bae, J. Analysis of Finger Muscular Forces using a Wearable Hand Exoskeleton System. J. Bionic Eng. 2017, 14, 680-691. [CrossRef]

87. Secciani, N.; Bianchi, M.; Ridolfi, A.; Volpe, F.V.Y.; Governi, L.; Bianchini, M.; Allotta, B. Tailor-Made Hand Exoskeletons at the University of Florence: From Kinematics to Mechatronic Design. Machines 2019, 7, 22. [CrossRef]

88. Wei, W.; Guo, S.; Zhang, F.; Guo, J.; Ji, Y.; Wang, Y. A novel upper limb rehabilitation system with hand exoskeleton mechanism. In Proceedings of the 2013 IEEE International Conference on Mechatronics and Automation, Takamatsu, Japan, 4-7 August 2013; pp. 285-290.

89. Bouzit, M.; Burdea, G.; Popescu, G.; Boian, R. The Rutgers Master II-new design force-feedback glove. IEEE/Asme Trans. Mechatron. 2002, 7, 256-263. [CrossRef]

90. Pratt, G.A.; Williamson, M.M. Series elastic actuators. In Proceedings of the 1995 IEEE/RSJ International Conference on Intelligent Robots and Systems. Human Robot Interaction and Cooperative Robots, Pittsburgh, PA, USA, 5-9 August 1995; p. 399.

91. Lee, D.W.; Lee, S.J.; Yoon, B.R.; Jho, J.Y.; Rhee, K. Preliminary Study on Analysis of Pinching Motion Actuated by Electro-Active Polymers. Int. J. Mech. Mechatron. Eng. 2014, 8, 919-921. 